\title{
Indoleamine 2,3-dioxygenase regulates anti-tumor immunity in lung cancer by metabolic reprogramming of immune cells in the tumor microenvironment
}

\author{
Cara C. Schafer ${ }^{1}$, Yong Wang ${ }^{1}$, Kenneth P. Hough ${ }^{1}$, Anandi Sawant ${ }^{2}$, Stefan C. \\ Grant $^{1}$, Victor J. Thannickal' ${ }^{1}$, Jaroslaw Zmijewski ${ }^{1}$, Selvarangan Ponnazhagan ${ }^{2}$, \\ Jessy S. Deshane ${ }^{1}$ \\ ${ }^{1}$ Department of Medicine, University of Alabama at Birmingham, Birmingham, AL, USA \\ ${ }^{2}$ Department of Pathology, University of Alabama at Birmingham, Birmingham, AL, USA \\ Correspondence to: Jessy S. Deshane, email: treena@uab.edu \\ Keywords: indoleamine 2,3-dioxygenase, myeloid-derived suppressor cells, lung cancer, metabolism, combination therapy \\ Received: March 01, 2016 \\ Accepted: September 13, 2016 \\ Published: September 26, 2016
}

\section{ABSTRACT}

Indoleamine 2,3-dioxygenase (IDO) has been implicated in immune evasion by tumors. Upregulation of this tryptophan (Trp)-catabolizing enzyme, in tumor cells and myeloid-derived suppressor cells (MDSCs) within the tumor microenvironment (TME), leads to Trp depletion that impairs cytotoxic $\mathrm{T}$ cell responses and survival; however, exact mechanisms remain incompletely understood. We previously reported that a combination therapy of gemcitabine and a superoxide dismutase mimetic promotes anti-tumor immunity in a mouse model of lung cancer by inhibiting MDSCs, enhancing polyfunctional response of $\mathrm{CDB}^{+}$memory $\mathrm{T}$ cells, and extending survival. Here, we show that combination therapy targets IDO signaling, specifically in MDSCs, tumor cells, and $\mathrm{CD}^{+} \mathrm{T}$ cells infiltrating the TME. Deficiency of IDO caused significant reduction in tumor burden, tumor-infiltrating MDSCs, GM-CSF, MDSC survival and infiltration of programmed death receptor-1 (PD-1)-expressing $\mathrm{CD8}^{+} \mathrm{T}$ cells compared to controls. IDO ${ }^{-/}$MDSCs downregulated nutrient-sensing AMP-activated protein kinase (AMPK) activity, but IDO ${ }^{-/} \mathrm{CD8}^{+} \mathrm{T}$ cells showed AMPK activation associated with enhanced effector function. Our studies provide proof-of-concept for the efficacy of this combination therapy in inhibiting IDO and T cell exhaustion in a syngeneic model of lung cancer and provide mechanistic insights for IDO-dependent metabolic reprogramming of MDSCs that reduces $\mathrm{T}$ cell exhaustion and regulates anti-tumor immunity.

\section{INTRODUCTION}

The metabolic state and activities of the immune cells comprising the tumor microenvironment (TME) influences the proliferative and invasive capacity of tumor cells. Tumors evade immune detection through various mechanisms of immune suppression including upregulation of indoleamine 2,3-dioxygenase (IDO), a heme-containing enzyme that catalyzes the conversion of the essential amino acid tryptophan (Trp) into the metabolic byproduct kynurenine (Kyn) [1]. IDO overexpression, in both hematopoietic and nonhematopoietic compartments [2], can alter metabolic properties of immune and tumor cells to promote tumor progression [3]. Increased IDO expression and activity are correlated with poor patient prognosis and quality of life $[4,5]$. IDO has been identified as a pathogenic driver of MDSC expansion leading to cancer progression by mediating IL-6 driven MDSC suppressive function [6]. Not only does IDO activation deplete essential Trp from the TME, but it also causes accumulation of Kyn which generates a tumor-promoting environment by converting naïve $\mathrm{CD}^{+} \mathrm{T}$ cell development into regulatory $\mathrm{T}$ cells $\left(\mathrm{T}_{\text {regs }}\right)$ that facilitate tolerance to tumors and counteract anti-tumor immune cells $[1,7]$. In addition to IDO, upregulation of programmed death ligand-1 and its engagement with the inhibitory receptor programmed death receptor-1 (PD-1) have also been identified as immune inhibitory mechanisms that downregulate active T cell responses $[8,9]$. 
Recent studies investigating nutrient-signaling responses to Trp availability have identified independent roles for mechanistic target of rapamycin (mTOR) and general control non-derepressible 2 (GCN2) kinases in cancer cells $[10,11]$. When Trp levels are sufficient (Trp sufficiency), activated mTOR phosphorylates ribosomal S6 kinase, which phosphorylates downstream ribosomal protein S6 (pS6) [12]. S6 activation turns on cellular growth, proliferation, and protein synthesis [13]. When Trp levels are reduced following induction of IDO [3], resulting in Trp deficiency, stores of uncharged TrptRNA become elevated and this prompts the integrated stress response to stimulate GCN2 kinase [14]. Activated GCN2 subsequently phosphorylates eukaryotic initiation factor 2 alpha (peIF2 $\alpha$ ), limiting cell growth and protein translation [14].

Alternate mechanisms involving nutrient sensor AMP-activated protein kinase (AMPK) can control mTOR, most notably, by activating mTOR inhibitory complexes [18, 19]. In cancer, AMPK serves as a key metabolic regulator in maintaining energy homeostasis during cellular stress [18]. AMPK functions to restore depleted ATP levels [20] and becomes activated when upstream liver kinase B1 (LKB1) tumor suppressor is phosphorylated [18]. Activated AMPK has different downstream functions, including phosphorylation of 6-phosphofructo-2-kinase/fructose-2,6-biphosphatase 2 (pPFKFB2), an enzyme involved in glycolytic flux [21]. Since AMP-activated protein kinase (AMPK) and mTOR are key regulators of nutrient-sensing [18], Trp availability will influence these pathways. AMPK has been shown to have both pro-tumorigenic and anti-tumorigenic roles in cancer [22], but mechanisms by which AMPK influences tumor cell responses remain unclear. In $\mathrm{CD}^{+} \mathrm{T}$ cells, AMPK has been shown to be essential for survival and memory recall [23].

We previously demonstrated the effectiveness of a combination therapy of gemcitabine (GEM) and a superoxide dismutase mimetic (SOD) in reducing tumor infiltrating MDSCs and $\mathrm{T}_{\text {regs }}$, while enhancing the quantity and quality of cytotoxic $\mathrm{CD}^{+} \mathrm{T}$ cell response in the $\mathrm{TME}$, in a murine model of lung cancer [15]. Since IDO is expressed in immunosuppressive cell types, including MDSCs $[9,16]$ and $\mathrm{T}_{\text {regs }}[17]$ as well as tumors, we explored the effects of inhibition of IDO pathway in these cells.

In this study, we demonstrated that our combination therapy significantly inhibited IDO, mTOR, and AMPK pathways in mice injected with Lewis lung carcinoma cells (LLCs). We investigated the impact of IDO on these signaling pathways in MDSCs, LLCs, and $\mathrm{CD}^{+} \mathrm{T}$ cells purified from the TME of wild type (WT) and IDOdeficient $\left(\mathrm{IDO}^{-/}\right)$mice. We identified that IDO deficiency not only diminished tumor burden, but also significantly limited the infiltration of MDSCs in tumor tissue. Reduced infiltration of both the PD- $1^{\text {hi }} \mathrm{CD}^{+}$and $\mathrm{CD}^{+} \mathrm{T}$ cells was noted in $\mathrm{IDO}^{-/}$mice. AMPK activation was reduced in IDO-deficient MDSCs compared to WT MDSCs. In contrast, tumor-infiltrating $\mathrm{CD}^{+} \mathrm{T}$ cells in IDO-deficient mice showed activation of AMPK with enhanced IFN- $\gamma$ and lactate production. We report that combination therapy reduced IDO and mTOR pathway activation in MDSCs and LLCs and further significantly enhanced IFN- $\gamma$ and glycolytic lactate production by $\mathrm{CD} 8^{+} \mathrm{T}$ cells. These data suggest that direct targeting of MDSCs and lung cancer cells by combination therapy can inhibit IDO signaling and tumor cell proliferation pathways, while reducing $\mathrm{T}$ cell exhaustion and promoting enhanced glycolytic metabolism of cytotoxic $\mathrm{CD}^{+} \mathrm{T}$ cells.

Taken together, this study reveals a novel role for IDO in regulation of AMPK activation, distinct from Trp sufficiency and deficiency signaling through mTOR and GCN2. These data also provide mechanistic evidence that a combination treatment of gemcitabine and a SOD mimetic can metabolically reprogram the cellular components of the TME including suppressor cells, effector T cells, and tumor cells.

\section{RESULTS}

\section{Combination therapy inhibits IDO pathway and inhibition of IDO impairs tumor growth and tumor infiltration of MDSCs}

We previously reported that infiltration of $\mathrm{Gr}^{+} \mathrm{CD} 11 \mathrm{~b}^{+} \mathrm{MDSC}$ increased with tumor progression in a syngeneic, intracardiac (i.c.) murine model of lung cancer [15]. Specifically, combination therapy $(\mathrm{S}+\mathrm{G})$ of gemcitabine (GEM) and a SOD mimetic (SOD) inhibited tumor-infiltrating MDSCs [15]. This enhanced anti-tumor immunity by promoting proliferation and persistence of multi-functional $\mathrm{CD}^{+} \mathrm{T}$ cells, resulting in prolonged survival [15]. To investigate the mechanisms underlying this enhanced cytotoxic $\mathrm{CD} 8^{+} \mathrm{T}$ cell response, we first determined if combination therapy inhibits IDO pathway in the TME. After transplant of LLCs into WT mice, tumors grew rapidly over two weeks (Supplementary Figure S1A). Tumor burden was reduced following administration of combination therapy (Supplementary Figure S1B). Immunoblot analyses showed reduction of IDO expression in tumor (Figure 1A, Supplementary Figure S1C), lung, and spleen tissues (Supplementary Figure S1D). In the tumor tissue, expression of IDO1 was greater than its isoform IDO2 (Figure 1A), suggesting a regulatory role for IDO1 in mediating immunosuppression and inducing downstream GCN2 expression. Additionally, serum IDO activity was reduced following combination therapy (Supplementary Figure S1E) compared to gemcitabine-treated controls. The significant reduction of IDO activity and lung IDO expression by the SOD mimetic alone may also reflect a unique advantage of this antioxidant mimetic in altering IDO function in oxidantrich lung tumors. 
A.

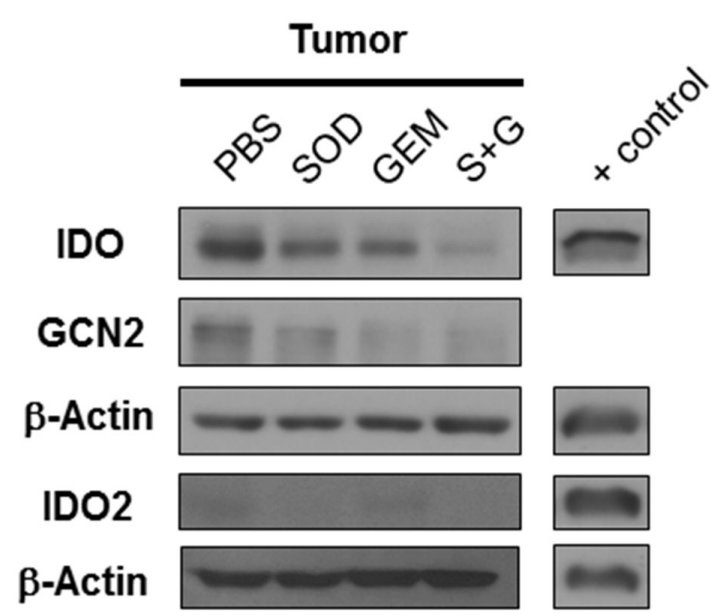

B.

Day 9

Day 11

Day 9
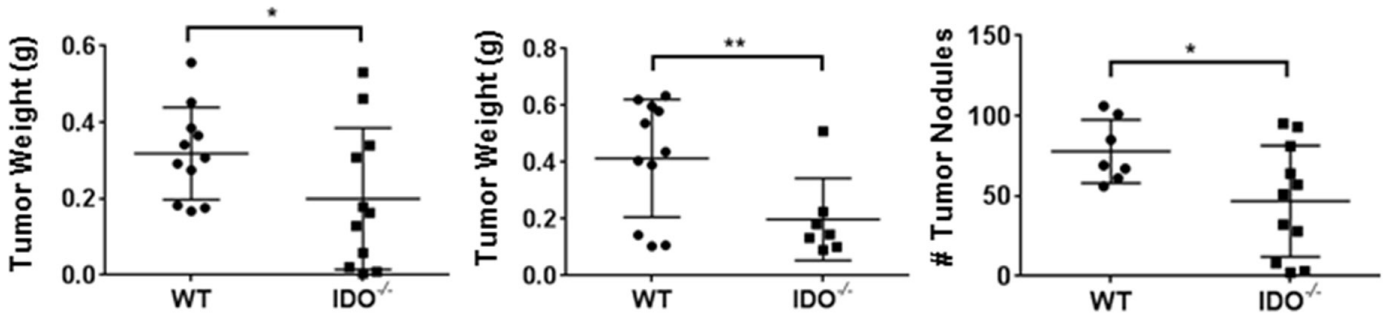

C.
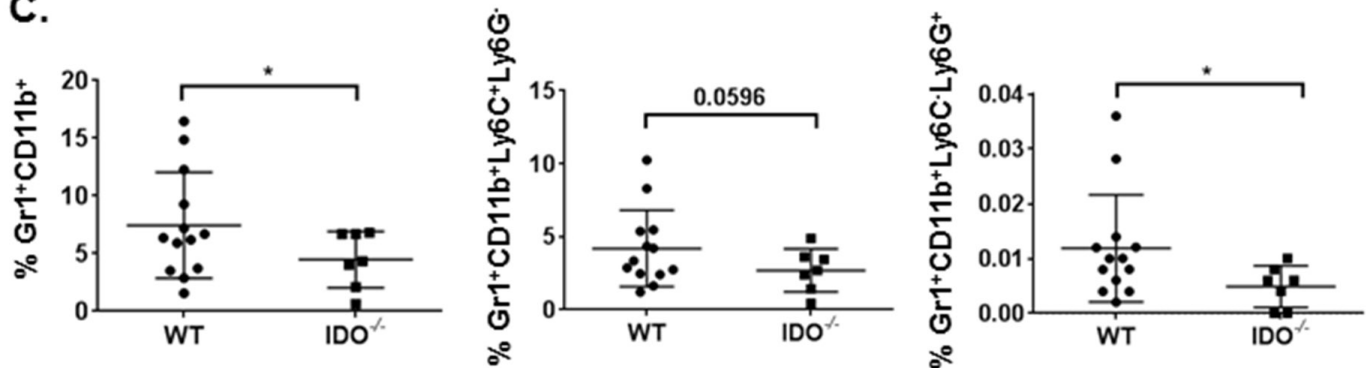

D.

E.
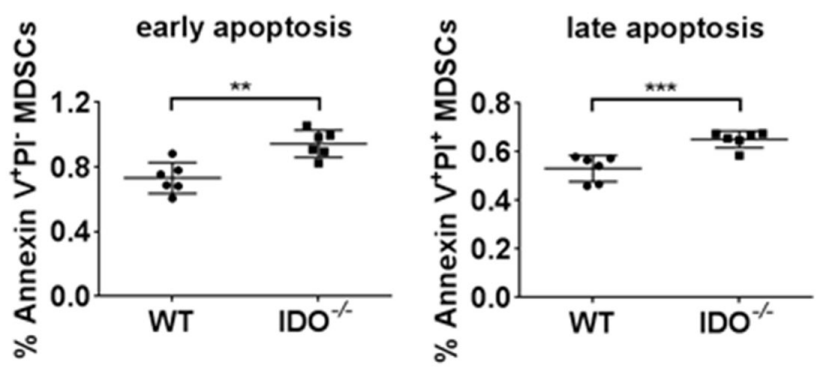

Figure 1: Combination therapy reduces tumor IDO expression and IDO deficiency inhibits tumor burden along with MDSC infiltration and survival in the TME. Mice were injected i.c. with $1 \times 10^{6}$ LLCs and treated with PBS, SOD mimetic (SOD), gemcitabine (GEM), or SOD mimetic and gemcitabine $(\mathrm{S}+\mathrm{G})$. Tumor lysates were collected on day-9 for Western Blot analysis. A. IDO pathway is inhibited in tumor by combination treatment. B. WT mice have larger tumors and more nodules compared to IDO $\approx$ mice (three pooled independent experiments, $\mathrm{n}=7-11$ mice/group) on day-9 and day-11 post-i.c. injection analyzed by student's unpaired t-test. C. By flow cytometry, total percentages of tumor-infiltrating MDSCs from the live cell gate, and both monocytic and granulocytic MDSCs, are diminished in $\mathrm{IDO}^{-}$mice (pooled independent experiments, $\mathrm{n}=7-13$ mice/group) on day-11 post-i.c. injection. Data in $\mathrm{B}$ and $\mathrm{C}$ are compared using a student's unpaired t-test with Welch's correction, ${ }^{*} \mathrm{P}<0.05, * * \mathrm{P}<0.001$. In lung homogenates from day-11 post-tumor implant, D. IDO $\_$mice $(n=4)$ exhibit lower ELISA concentrations of GM-CSF compared to WT ( $\left.\mathrm{n}=3\right)$. E. By flow cytometry, IDO-deficient bone marrow-differentiated MDSCs demonstrate higher total percentages of apoptotic MDSCs (6 replicates/group). Data in D and E are analyzed by student's unpaired t-test, ${ }^{*} \mathrm{P}<0.05,{ }^{*} \mathrm{P}<0.005,{ }^{* * *} \mathrm{P}<0.001$. 
Tumor-promoting MDSCs and tumor cells expressing IDO can enhance tumor growth [24-27]. We evaluated IDO expression in MDSCs and tumor cells from the TME. Immunoblot analyses showed predominant IDO expression in the tumor nodules and in the purified tumor-associated $\mathrm{Gr}^{+} \mathrm{CD}_{11 \mathrm{~b}^{+}} \mathrm{MDSCs}$ from WT mice (Supplementary Figure S2A), while IDO expression was reduced in the $\mathrm{Gr1} 1^{-} \mathrm{CD} 11 \mathrm{~b}^{-}$population, representing all other cells in the TME including transplanted tumor cells. To determine the impact of IDO on tumor growth, we confirmed that IDO1, not IDO2, was induced following tumor establishment in the lungs of both WT and IDOdeficient mice (Supplementary Figure S2B). Since all host tissues and tumor-infiltrating immune cells lack Idol in $\mathrm{IDO}^{-/}$mice, these data suggest that only the transplanted LLC tumor cells contribute to IDO expression in the $\mathrm{IDO}^{-/}$mice. IFN- $\gamma$, a known stimulator of IDO, activates the JAK/STAT pathway to regulate IDO at both the transcriptional and translational level [28]. Although baseline IDO expression was undetectable in LLCs, IDO was induced in LLCs treated with recombinant mouse IFN- $\gamma$ (Supplementary Figure S2C), suggesting that cytokines and other factors in the TME can induce IDO in tumor cells transplanted into IDO-deficient mice. There was no difference in IFN- $\gamma$ production comparing tumorbearing WT and $\mathrm{IDO}^{-/}$mice (Supplementary Figure S2D). As tryptophan dioxygenase (TDO) is another enzyme that may produce kynurenine, we investigated TDO2 expression in the lungs of tumor bearing WT and $\mathrm{IDO}^{-/}$ mice. As shown in Supplementary Figure S2E, although TDO2 expression was noted in the naïve lung tissues of $\mathrm{WT}$ and $\mathrm{IDO}^{-/}$mice, significantly reduced expression was observed in tumor bearing mice.

At day-9, IDO-deficient mice exhibited diminished tumor burden and fewer tumor nodules (Figure 1B). Even at day-11, tumor burden was reduced in mice lacking IDO (Figure 1B). Therefore, IDO expression from transplanted LLCs in the IDO-deficient mice was not sufficient to promote tumor growth, validating the predominant role for IDO-expressing MDSCs in enhancing tumor growth. Similar results were also observed using an intravenous model of tumor implantation (Supplementary Figure S3A). We then investigated whether IDO deficiency would impact immune cell infiltration in the TME. Tumor infiltration of total immunosuppressive MDSCs, and percentages of both granulocytic (Ly6G $\left.\mathrm{Ly}^{+} \mathrm{C}^{-}\right)$and monocytic (Ly6G-Ly6C ${ }^{+}$) MDSC subsets, were diminished in $\mathrm{IDO}^{-/}$mice (Figure $1 \mathrm{C}$ and Supplementary Figure S3B). Similarly, our combination therapy also reduced the percentages of MDSCs in tumor, lung, and spleen tissues [15]. Levels of granulocyte-macrophage colonystimulating factor (GM-CSF), a pro-inflammatory cytokine known to drive MDSC differentiation and expansion [29, 30], were reduced in lung tissues from tumor-bearing $\mathrm{IDO}^{-/}$mice compared to WT controls (Figure 1D). Lower GM-CSF concentrations could account for diminished presence of MDSCs in IDO $/$ mice. Since GM-CSF levels were altered, we determined the impact of IDO on overall survival of MDSCs. In in vitro-differentiated MDSCs from bone marrow, increase in MDSC cell death, characterized by Annexin V and PI staining was noted in $\mathrm{IDO}^{-/}$mice (Figure 1E). Together, these data demonstrate a critical role for IDO in MDSC infiltration and survival in LLC tumor-bearing mice.

\section{IDO deficiency limits $\mathrm{CD8}^{+}$and $\mathrm{CD4}^{+} \mathrm{T}$ cell exhaustion in tumor-bearing mice}

To determine the impact of IDO deficiency on immunosuppression by MDSCs, we measured tumorinfiltrating $\mathrm{CD}^{+} \mathrm{T}$ cells. Percentages of $\mathrm{CD}^{+} \mathrm{T}$ cells and percentages of polyfunctional effector $\mathrm{T}$ cells producing effector cytokines IL- 2 , IFN- $\gamma$, and TNF- $\alpha$ were significantly elevated in $\mathrm{IDO}^{-/}$mice, (Figure 2A). IDO deficiency also elevated tumor-infiltrating central memory and stem cell memory $\mathrm{T}$ cells $\left(\mathrm{T}_{\mathrm{CM}}\right.$ and $\left.\mathrm{T}_{\mathrm{SCM}}\right)$ but caused a reduction of effector memory $\mathrm{T}$ cells $\left(\mathrm{T}_{\mathrm{EM}}\right)$ (Figure $2 \mathrm{~B}$ ). Treatment with IDO inhibitor, 1-methyl-D-tryptophan (D1MT), enhanced percentages of only TNF- $\alpha^{+}$and perforin ${ }^{+} \mathrm{CD}^{+} \mathrm{T}$ cells compared to IDO deficient mice. Similarly, although D1MT treatment enhanced effector memory $\mathrm{CD}^{+} \mathrm{T}$ cells compared to $\mathrm{IDO}^{-/-}$mice, it did not have comparable effects for induction of the other memory cell subsets. Because IDO-expressing MDSCs induce suppressive mechanisms to downregulate $\mathrm{T}$ cell function and promote anergy [31], we investigated whether $\mathrm{CD}^{+} \mathrm{T}$ cell exhaustion was alleviated in IDO-deficient mice. We evaluated expression of checkpoint molecules PD-1, LAG3, TIM-3, and CTLA-4. Figure 2C and 2D show that PD-1 expression and percentages of the $\mathrm{CD}^{+}$and $\mathrm{CD} 8^{+} \mathrm{PD}-1^{\text {hi }}$ $\mathrm{T}$ cells (Supplementary Figure S4A), were reduced in the spleens of tumor-bearing IDO-deficient mice, as well as the total percentages and ratio of total percentages to spleen weights of PD- $1^{+}$and $\mathrm{PD}-1^{\text {hi }} \mathrm{CD} 8^{+} \mathrm{T}$ cells. These results suggest that checkpoint molecule $\mathrm{PD}-1$ is impaired on $\mathrm{CD}^{+}$lymphocytes in both the spleen and tumor tissues which may dampen $\mathrm{T}$ cell exhaustion to promote effector $\mathrm{T}$ cell polyfunctionality in the TME. Additionally, in the tumors, percentages of $\mathrm{CD} 8^{+} \mathrm{LAG}-3^{+} \mathrm{T}$ cells were also reduced in $\mathrm{IDO}^{-/-}$mice, without any significant differences in additional checkpoint molecules TIM-3 and CTLA4 (Supplementary Figure S4B). These data emphasize the importance of targeting IDO-expressing MDSCs to overcome $\mathrm{T}$ cell exhaustion.

\section{Tumor-derived MDSCs lacking IDO exhibit reduced activation of AMPK pathway}

Next, we investigated mechanisms of metabolic modulation by IDO. MDSCs and tumor cells in the TME can both alter Trp metabolism by upregulating IDO to induce tolerance to tumor-specific $\mathrm{T}$ cells $[25,26,32]$. 

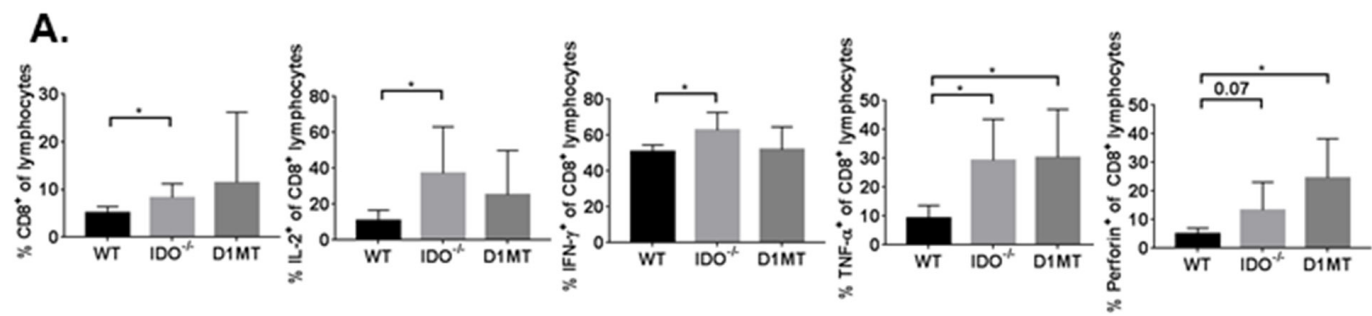

\section{B.}
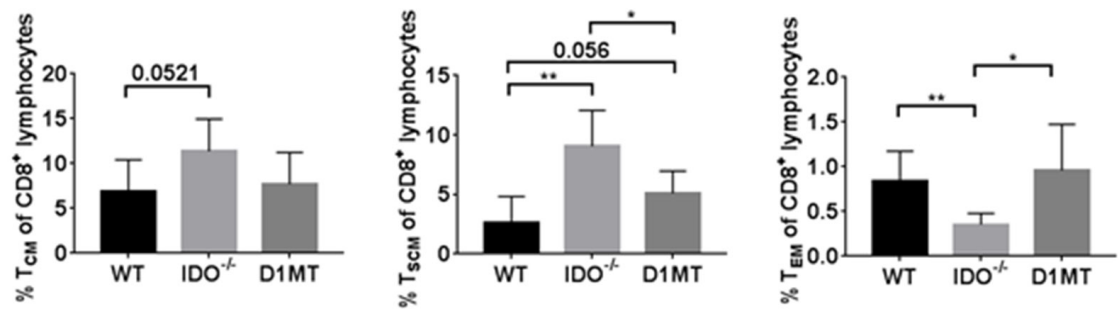

C.
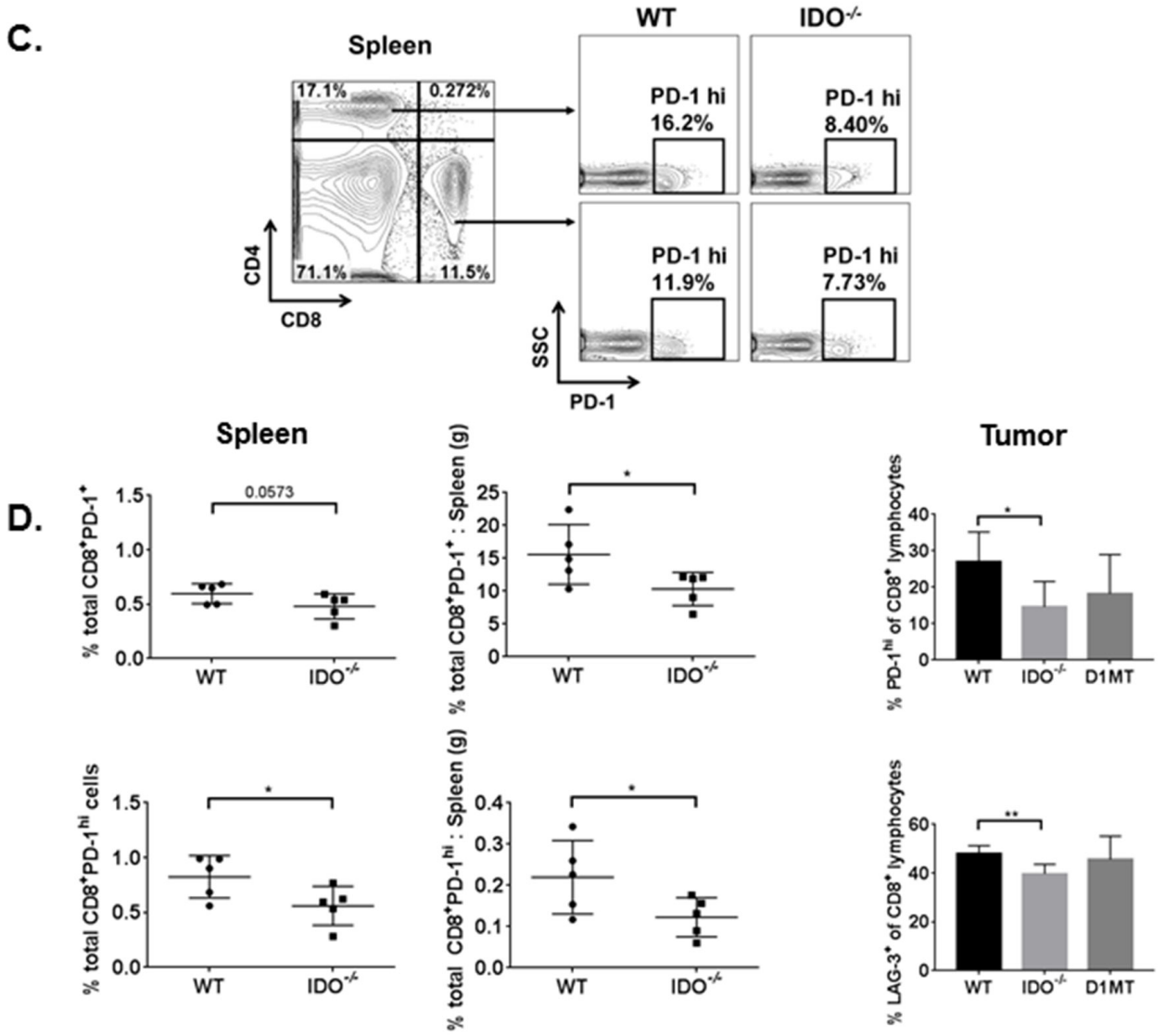

Figure 2: Tumor-bearing IDO ${ }^{-}$T lymphocytes are more polyfunctional, have enhanced memory, and express fewer T cell surface exhaustion markers. On day-9 from i.c.-injected WT, IDO ${ }^{-}$, and D1MT treated ( $\mathrm{n}=4-5$ mice/group), tumor cells were analyzed by flow cytometry for intracellular cytokines and memory $\mathrm{T}$ cell subsets, as described. The percentages are calculated for A. IL-

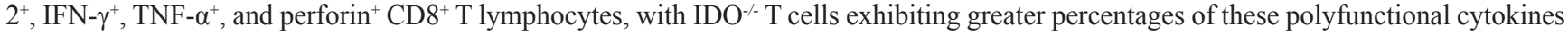
in the TME. Data are analyzed by student's unpaired t-test, ${ }^{*} \mathrm{P}<0.05$. B. Compared to WT, percentages of central memory $\left(\mathrm{T}_{\mathrm{CM}}\right)$ and stem cell memory $\left(\mathrm{T}_{\mathrm{SCM}}\right) \mathrm{CD} 8^{+} \mathrm{T}$ lymphocytes are elevated in $\mathrm{IDO}^{-}$mouse tumors, while effector memory $\mathrm{CD} 8^{+} \mathrm{T}$ lymphocyte $\left(\mathrm{T}_{\mathrm{EM}}\right)$ subsets are reduced in $\mathrm{IDO}^{-}$mice. For $\mathrm{T}_{\mathrm{CM}}$, WT vs IDO $\nsim$ data are analyzed by student's unpaired t-test. For $\mathrm{T}_{\mathrm{SCM}}$, WT vs IDO $\nsim$ and $\mathrm{IDO}^{-}$vs D1MT are compared by student's unpaired t-test and WT vs D1MT is compared by Mann-Whitney, ${ }^{*} \mathrm{P}<0.05, * * \mathrm{P}<0.005$. For $\mathrm{T}_{\mathrm{EM}}$, WT vs IDO^ data are analyzed by Mann-Whitney and WT vs D1MT values are compared by student's unpaired t-test, ${ }^{*} \mathrm{P}<0.05, * * \mathrm{P}<0.01$. On day-9 following tumor i.c. implant in WT and $\mathrm{IDO}^{-}$mice ( $\mathrm{n}=5$ mice/group), spleens were analyzed for PD-1 surface expression on $\mathrm{CD}^{+}$and $\mathrm{CD} 8^{+} \mathrm{T}$ cells, as demonstrated by the gating strategy in C. $\mathbf{D}$. IDO ${ }^{-/}$mice show much lower total PD- $1^{+}$and PD- $1^{\text {hi }}$ percentages for CD $8^{+} \mathrm{T}$ cells (and as a ratio to corresponding spleen weight). Similarly, in the tumor, IDO deficiency impairs the percentages of PD- $1^{\text {hi }}$ and LAG- $3^{+}$ surface expression on $\mathrm{CD} 8^{+} \mathrm{T}$ cells. Data are analyzed by student's unpaired t-test, ${ }^{*} \mathrm{P}<0.05, * * \mathrm{P}<0.01$. 
Over-activation of IDO inhibits the mTOR pathway which regulates Trp sufficiency signaling [10, 33, 34]. We first examined how cellular mTOR phosphorylation of S6 (Trp sufficient signaling) and how cellular GCN2 phosphorylation of eIF $2 \alpha$ (Trp deficient signaling) would be affected in the absence of host IDO. By fluorescenceactivated cell sorting (FACS), MDSCs were characterized by initially gating on CD45, or leukocyte common antigen, expressed only on cells of hematopoietic origin. From the $\mathrm{CD}_{4} 5^{+}$population, MDSCs were positively identified by $\mathrm{Gr}-1^{+} \mathrm{CD} 11 \mathrm{~b}^{+}$surface expression while $\mathrm{T}$ cells (in the lymphocyte gate) were characterized by surface expression of $\mathrm{CD} 8$. We immunosorted $\mathrm{CD} 45^{+} \mathrm{Gr} 1^{+} \mathrm{CD} 11 \mathrm{~b}^{+} \mathrm{CD} 8$ MDSCs from the tumor tissues of WT and $\mathrm{IDO}^{-/}$mice. As shown in Figure 3A, in $\mathrm{IDO}^{-/} \mathrm{MDSCs}$, there was a significant reduction in GCN2 expression which led to decreased activation of Trp deficiency signal, measured by phosphorylation of eIF $2 \alpha$ (peIF $2 \alpha$ ). MDSCs showed no difference in activation of mTOR effector molecule ribosomal S6 (pS6) in both strains of mice, suggesting that Trp sufficiency and deficiency signaling is independently regulated by IDO. MDSCs from $\mathrm{IDO}^{-/}$mice exhibited reduced activation of the AMPK pathway, including upstream LKB1 and downstream PFKFB2 (Figure 3B). MDSCs isolated from the bone marrow of tumor-bearing $\mathrm{IDO}^{-/}$mice also showed diminished activation of AMPK compared to WT (Supplementary Figure S5). These data suggest the possibility of an inherent deficit in AMPK activation in IDO-deficient MDSCs that is not limited to AMPK impairment within MDSCs residing in the TME.

\section{AMPK signaling and effector functions of tumor-specific $\mathrm{CD8}^{+} \mathrm{T}$ cells are turned on in IDO-deficient mice}

Because IDO-expressing MDSCs contribute to $\mathrm{CD}^{+} \mathrm{T}$ cell tolerance, we investigated how IDO deficiency influenced metabolic signaling in $\mathrm{CD} 8^{+} \mathrm{T}$ cells within the TME. Here, we FACS-purified CD $45^{+} \mathrm{CD} 8^{+} \mathrm{Gr}-1^{-} \mathrm{CD} 11 \mathrm{~b}^{-} \mathrm{T}$ cells from the tumor tissue. As shown in Figure $3 \mathrm{C}$, the absence of IDO in $\mathrm{CD}^{+} \mathrm{T}$ cells did not influence GCN2 expression. In fact, eIF $2 \alpha$ activation in these cells was increased without affecting mTOR phosphorylation of S6. There was no difference in expression or activation of IDO, GCN2, or mTOR pathway in CD45- LLCs (Supplementary Figure S6), suggesting that the IDOdeficient immune cells are responsible for altered Trp signaling rather than the tumor cells. Since Trp deficiency signaling through eIF2 $\alpha$ was independent of Trp sufficiency signaling via mTOR in MDSCs, $\mathrm{CD}^{+} \mathrm{T}$ cells, and LLCs, this indicates an alternate pathway may be regulating metabolic signaling cues within these cells.

Knowing that Trp metabolism can influence downstream signaling we asked how IDO regulates nutrient metabolism in these cells within the TME. AMPK, an energy and nutrient sensor, is critical for survival of activated $\mathrm{CD}^{+} \mathrm{T}$ cells [35] and plays a key role in metabolic reprogramming of naïve to effector and effector to memory $\mathrm{T}$ cells $[23,36]$. As shown in Figure $3 \mathrm{D}$, AMPK was differentially regulated within $\mathrm{IDO}^{-/-}$ $\mathrm{CD}^{+} \mathrm{T}$ cells compared to WT. $\mathrm{CD}^{+} \mathrm{T}$ cells from $\mathrm{IDO}^{-/}$ mice showed increased AMPK activation and amplified signals upstream and downstream of AMPK. Activation or phosphorylation of PFKFB2 can turn on glycolysis which is necessary for the conversion of glucose to lactate $[7,21]$. Activated $\mathrm{CD}^{+} \mathrm{T}$ cells, like tumor cells, typically utilize glycolysis to generate energy [7]. CD8 ${ }^{+}$ $\mathrm{T}$ cells from IDO-deficient mice, as well as combination therapy treated mice, produced significantly higher levels of IFN- $\gamma$ and lactate, a metabolic end product of glycolysis [7], (Supplementary Figure S7B). Importantly, cellular lactate concentrations were reduced in tumor-purified LLCs from $\mathrm{IDO}^{-/}$mice (Supplementary Figure S7C). Notably, PFKFB2 activation was not different between WT and IDO ${ }^{-/}$LLCs (Supplementary Figure S6B). These data suggest that $\mathrm{CD}^{+} \mathrm{T}$ cells from tumor-bearing $\mathrm{IDO}^{-/}$ mice are more likely to have enhanced anti-tumor effects compared to those from tumor-bearing WT controls. Taken together, AMPK-driven metabolic alterations in MDSCs and $\mathrm{CD}^{+} \mathrm{T}$ cells of $\mathrm{IDO}^{-/}$mice may cause perturbations in the TME that contribute to the reduced tumor burden, percentages of MDSCs, and percentages of exhausted $\mathrm{CD}^{+} \mathrm{T}^{-}$cells in $\mathrm{IDO}^{-/}$mice.

Our studies provide the first evidence linking AMPK and IDO pathways in immune cells. Since combination therapy altered the metabolic status of memory $\mathrm{T}$ cells [15], we anticipated that this IDO-inhibiting therapy could also regulate AMPK and mTOR pathways in the TME.

\section{Combination therapy inhibits GCN2, mTOR, and AMPK pathway activation}

Next, we determined whether the combination therapy-mediated reduction of IDO expression and activity would modulate downstream amino acidsensing pathways, including GCN2, mTOR, and AMPK. Downstream of GCN2, peIF2 $\alpha$ was reduced in tumor tissues from combination therapy treated mice (Figure 4A). Even though combination therapy inhibits the IDO pathway and Trp deficiency signal peIF2 $\alpha$, it does not restore Trp sufficiency signaling via mTOR (Figure 4B). Consistent with our earlier findings in $\mathrm{IDO}^{-} /$mice, these data suggest that activation of the IDO pathway can be regulated independently of the Trp sufficiency signal pS6, as previously reported [10].

To rule out whether AMPK activation was responsible for the impaired activation of mTOR, we measured levels of phosphorylated and total AMPK. Phosphorylation of AMPK was reduced by combination treatment while the total AMPK levels remained unchanged (Figure 4C). As shown in Figure $4 \mathrm{D}$, downstream phosphorylation of PFKFB2 was also 


\section{A. \\ MDSCs}

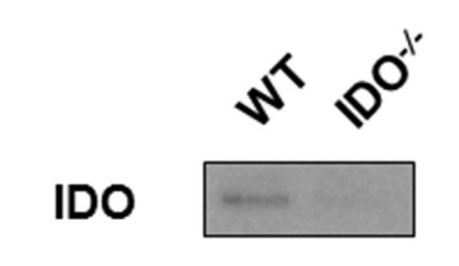

GCN2

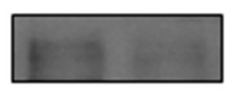

pelF $2 \alpha$

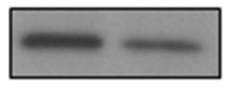

ps6

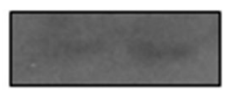

$\beta$-Actin

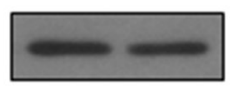

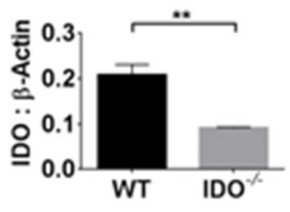
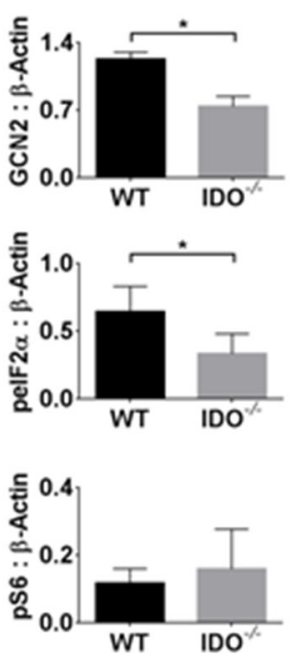

CD8 ${ }^{+} \mathrm{T}$ cells

c.

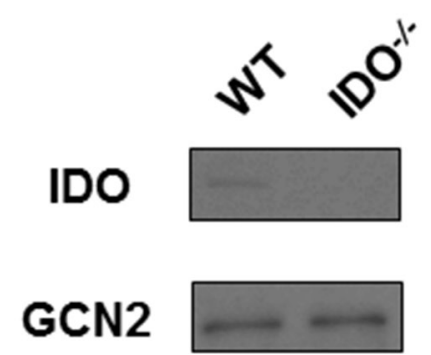

pelF $2 \alpha$

ps6

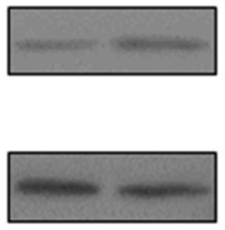

$\beta$-Actin

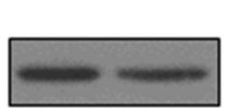

B.

\section{MDSCs}

pLKB1
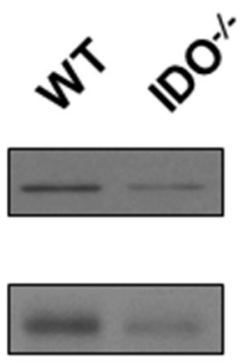

AMPK

pPFKFB2

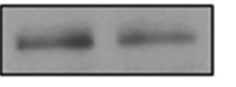

$\beta$-Actin

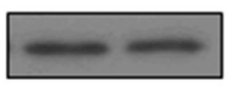

pAMPK
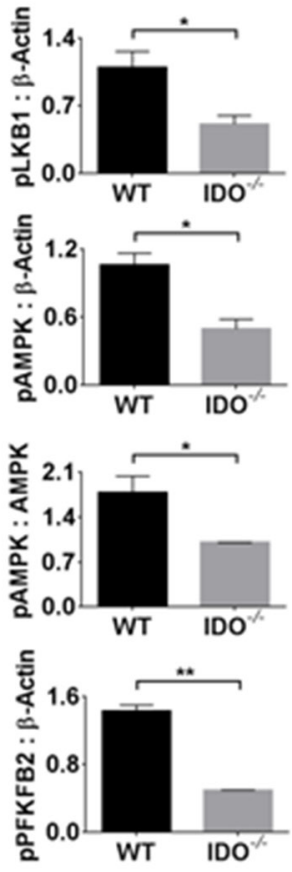

$\mathrm{CD8}^{+} \mathrm{T}$ cells
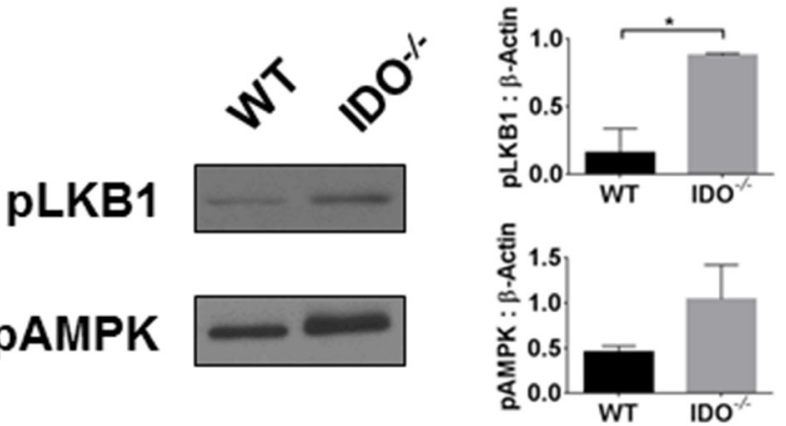

pAMPK

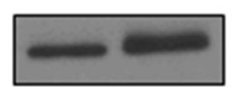

AMPK

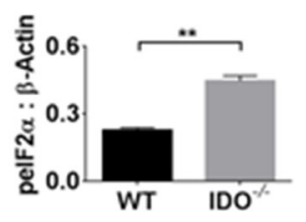

pPFKFB2
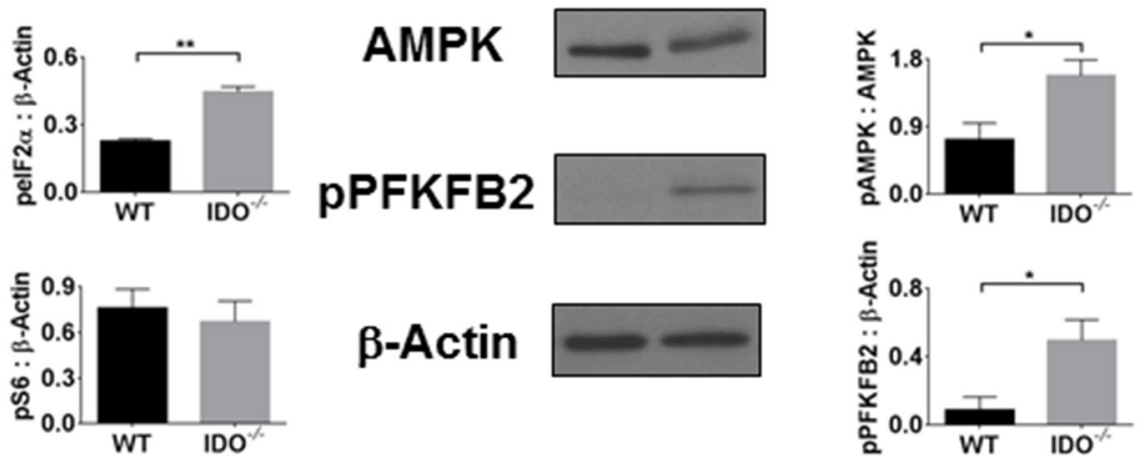

Figure 3: The AMPK pathway is inversely activated in IDO-deficient MDSCs and $\mathrm{CD8}^{+} \mathrm{T}$ cells, independent of mTOR activation status. On day-11, $\mathrm{CD}^{+} 5^{+} \mathrm{Gr}^{+} \mathrm{CD} 11 \mathrm{~b}^{+} \mathrm{MDSCs}$ were FACS-purified from i.c. tumors of WT and $\mathrm{IDO}^{-/}$mice and analyzed by Western Blot. A. IDO and GCN2 as well as B. AMPK pathway activation are reduced in IDO-deficient MDSCs, independent of mTOR. In addition, $\mathrm{CD}_{4} 5^{+} \mathrm{CD}^{+} \mathrm{T}$ cells were FACS-purified from tumors and expanded. C. Although GCN2 expression remains unchanged in $\mathrm{IDO}^{-/}$ $\mathrm{CD} 8^{+} \mathrm{T}$ cells, eIF2 $\alpha$ is activated. No difference in mTOR activation marker $\mathrm{pS} 6$ is observed. D. AMPK pathway is activated in $\mathrm{IDO}^{-} \mathrm{CD}^{+}$ $\mathrm{T}$ cells. Densitometry data, as a ratio of (phosphorylated) protein to $\beta$-Actin, are from at least two experimental replicates and compared by student's unpaired t-test, ${ }^{*} \mathrm{P}<0.05,{ }^{*} * \mathrm{P}<0.01$. 

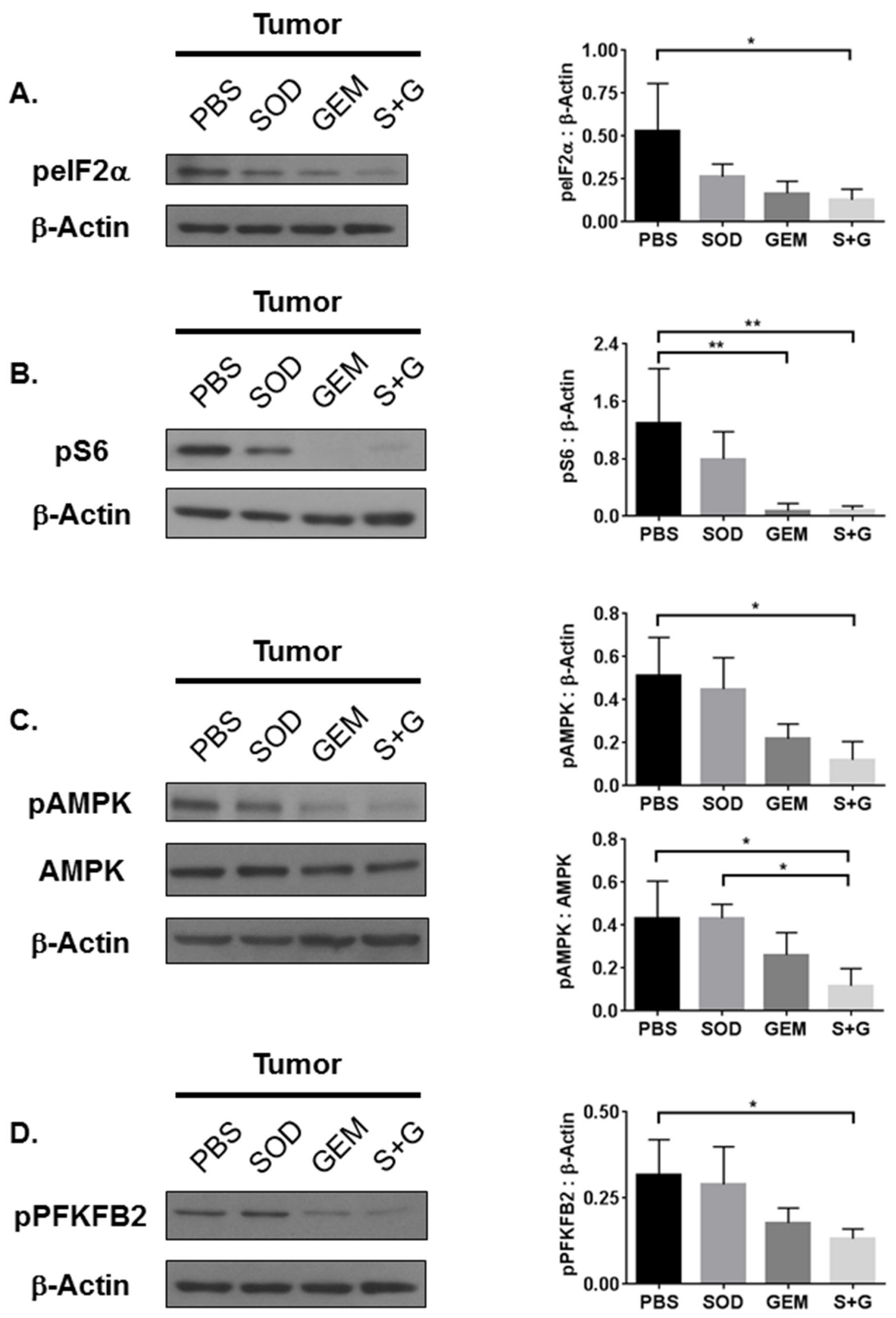

Figure 4: Combination treatment reduces tumor tissue GCN2, mTOR, and AMPK activation. Western Blot analyses of whole tumor lysates reveal that A. eIF2 $\alpha$, B. S6, C. AMPK, and D. PFKFB2 activation are inhibited by combination treatment. Densitometry data, as a ratio of phosphorylated protein to $\beta$-Actin or total protein expression, are from 3-4 replicate experiments and assessed by one-way ANOVA with Tukey's post-test, ${ }^{*} \mathrm{P}<0.05,{ }^{*} \mathrm{P}<0.01$. 
inhibited. We concluded that combination therapy affects both Trp metabolism and cellular energy metabolism, which could be influenced by immune cells in the TME.

\section{Combination therapy inhibits IDO pathway activation in MDSCs, tumor cells, and $\mathrm{CD8}^{+}$ T cells}

To determine the signaling pathways altered in response to individual and combination therapies, we purified MDSCs, CD45- LLCs, and $\mathrm{CD} 8^{+} \mathrm{T}$ cells from tumors and assessed activation status of IDO, GCN2, and mTOR pathways. We found that combination therapy inhibits IDO and GCN2 in all three cell types, but it reduces mTOR pathway activation only in MDSCs and LLCs (Figure 5A and Supplementary Figure S8). This broad inhibition of IDO by combination therapy led to the activation of Trp sufficiency signal pS6, specifically in $\mathrm{CD}^{+} \mathrm{T}$ cells and not in MDSCs or LLCs (Figure 5A and Supplementary Figure S8). Interestingly, since mTOR was activated in $\mathrm{CD}^{+} \mathrm{T}$ cells following combination therapy, robust activation of AMPK was not observed in $\mathrm{CD}^{+} \mathrm{T}$ cells (Supplementary Figure S7A).

These results support our initial observation that Trp sufficiency and deficiency signals must be mutually exclusive within these cell types. Phosphorylation of $\mathrm{S} 6$, by combination treatment in $\mathrm{CD}^{+} \mathrm{T}$ cells, can also positively regulate translation of IFN- $\gamma$ even when glucose levels are low [37]. We found that IFN- $\gamma$ secreted by $\mathrm{CD}^{+} \mathrm{T}$ cells from combination therapy treated mice is higher (Supplementary Figure S7B), consistent with elevated mTOR activation in these cells. Additionally, higher lactate levels in these cells persisted during $\mathrm{T}$ cell expansion (Supplementary Figure S7B), consistent with our previous observations [15].

\section{Combination therapy downregulates immune checkpoint molecules in the TME}

To address whether alterations in checkpoint molecules in IDO-deficient mice would be recapitulated in response to combination therapy, we analyzed $\mathrm{CD} 8^{+}$ lymphocytes within the tumor for immune checkpoint molecules PD-1, CTLA-4, LAG-3, and TIM-3. These checkpoint molecules were reduced by combination therapy in $\mathrm{CD}^{+} \mathrm{T}$ cells residing within the tumor (Figure $5 \mathrm{~B}$ ). This impairment of immune checkpoint molecules on $\mathrm{CD}^{+}$ $\mathrm{T}$ cells may contribute to the enhanced activation and metabolism to promote anti-tumor responses.

\section{Depletion of MDSCs and $\mathrm{CD8}^{+} \mathrm{T}$ cells does not promote tumor growth following combination therapy treatment}

Gemcitabine has been reported to have cytotoxic effects on proliferating tumor cells, which can directly influence tumor cell growth as well as depleting effects on MDSCs. To identify whether the observed effects by combination therapy are restricted to metabolic signaling alterations with immune cells, we depleted both MDSCs and $\mathrm{CD} 8^{+} \mathrm{T}$ cells using depleting antibodies and measured tumor burden compared to isotype and combination treatment controls. We confirmed depletion of MDSCs in the spleens of treated mice by flow cytometric staining for $\mathrm{Gr}-1^{+} \mathrm{CD} 11 \mathrm{~b}^{+}$cells (Figure 6A). While combination therapy significantly reduced monocytic and granulocytic MDSCs compared to isotype control, when MDSCs and $\mathrm{CD} 8^{+} \mathrm{T}$ cells were depleted and combination therapy was also administered, monocytic and granulocytic MDSCs were significantly reduced compared to combination therapy alone (Figure 6B). $\mathrm{CD} 8^{+} \mathrm{T}$ cell depletion was confirmed in the spleens of these mice (Figure 6C). Our data show that combination therapy significantly reduces tumor burden even when $\mathrm{CD}^{+} \mathrm{T}$ cells and MDSCs are depleted compared to mice which did not receive combination therapy. This reduction in tumor burden was significantly higher than mice depleted with both $\alpha \mathrm{Gr}-1$ and $\mathrm{CD} 8{ }^{+} \mathrm{T}$ cell depletion alone (Figure 6D). Immune cell depletion alone was not significantly different from isotype alone, suggesting that combination therapy must act directly on tumor cells within the TME. This is also evident in Figure 5A where combination therapy is the only therapy that is most effective at reducing IDO expression and signaling in LLCs purified from tumor. Taken together, combination therapy exerts effects not only on MDSCs and $\mathrm{CD} 8^{+} \mathrm{T}$ cells within the TME but also directly on the LLCs.

\section{DISCUSSION}

Among the emerging hallmarks of cancer, tumor immune evasion represents a unique target for the development of therapies designed to restore anti-tumor $\mathrm{T}$ cell functions [38]. Although immune-modulatory therapies appear promising, the precise mechanisms and signaling pathways subverted in immune cells, such as activated T cells and MDSCs, remain unclear. Monoclonal antibodies directed against CTLA-4 and PD-1/PD-L1, in addition to CAR $\mathrm{T}$ cells, are not exempt from IDOmediated immune resistance mechanisms [39-41]. Thus, novel therapies that target the IDO pathway, while enhancing $\mathrm{T}$ cell functionality and responsiveness, may be superior to existing immunotherapy strategies. This stresses the impending need to develop multi-modal therapies combining checkpoint inhibitors or $\mathrm{T}$ cellmodifying treatments. Elucidating the signaling pathways employed by immune cells within the TME may shed light on the manner in which host defenses and tumor cells respond to immune-modulating combination treatments. An understanding of how these pathways act in concert with each other can facilitate the development and design of improved drug-targeting strategies. 


\section{Tumor Microenvironment}

A.

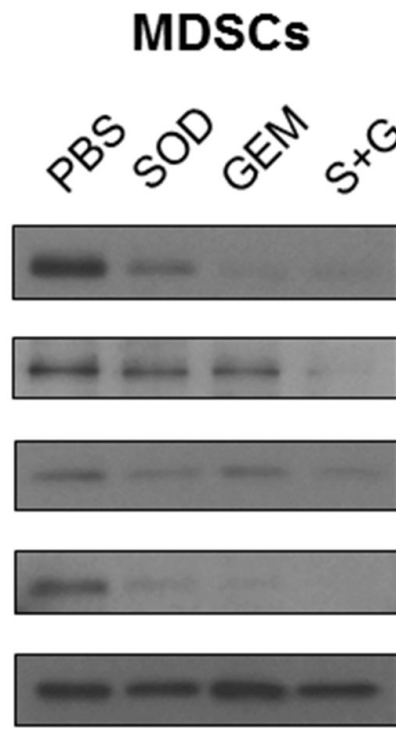

LLCs
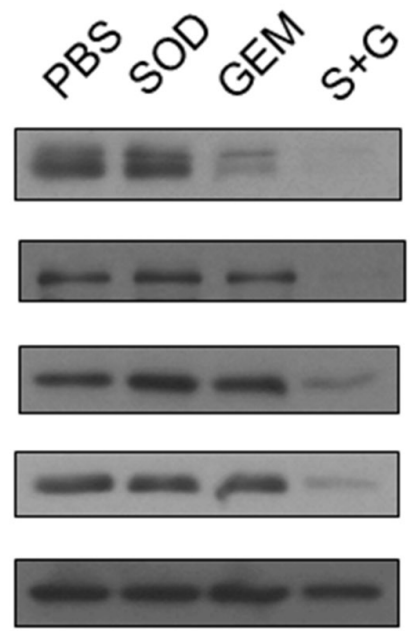

CD8 $^{+}$T cells
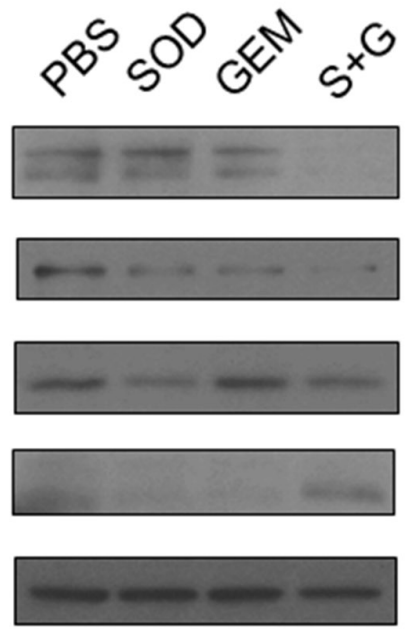

\section{Tumor}

B.
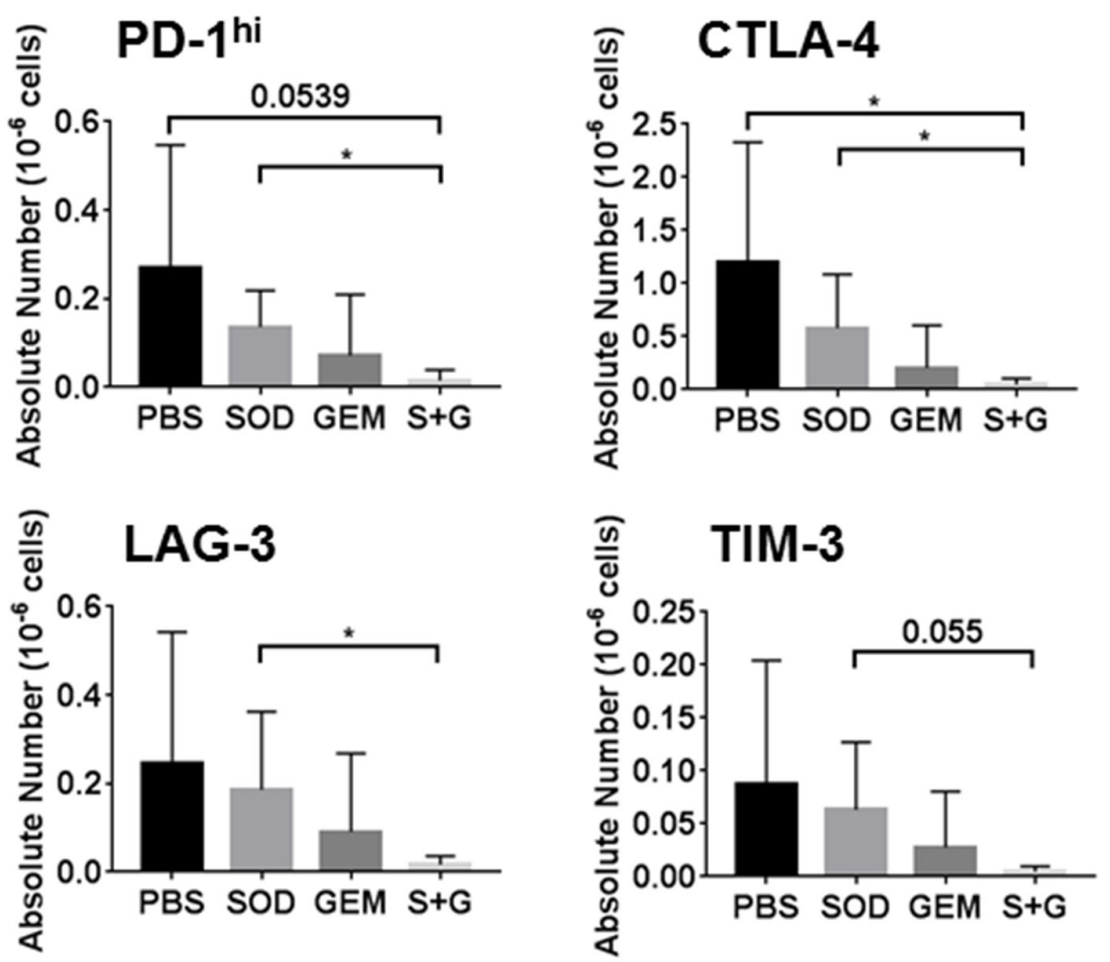

Figure 5: Combination treatment inhibits IDO and mTOR activation in MDSCs and LLCs but restores mTOR activation only in $\mathrm{CD8}^{+} \mathrm{T}$ cells. Combination therapy reduces expression of immune check point molecules. On day-14 post-i.c. LLC challenge, WT mice receiving individual and combination treatment were sacrificed and tumors were digested. Tumor-purified $\mathrm{CD}^{2} 5^{+} \mathrm{Gr}^{+} \mathrm{CD} 11 \mathrm{~b}^{+} \mathrm{MDSCs}, \mathrm{CD} 45^{+} \mathrm{CD} 8^{+} \mathrm{T}$ cells, and $\mathrm{CD} 45^{-} \mathrm{LLCs}$ were isolated by FACS. CD8 ${ }^{+} \mathrm{T}$ cells were expanded and prepared as lysates. A. Combination therapy reduces the expression of IDO, GCN2, and phosphorylation of both eIF $2 \alpha$ and S6 in MDSCs and LLCs. Combination therapy also impairs the IDO pathway in CD8 ${ }^{+} \mathrm{T}$ cells but restores S6 activation. B. On day-11 post i.c. LLC challenge, flow cytometric analyses of tumor $\mathrm{CD}^{+} \mathrm{T}$ cells also demonstrates that combination therapy treated mice have fewer absolute numbers of $\mathrm{CD} 8^{+} \mathrm{T}$ cells expressing checkpoint molecules PD- $1^{\text {hi }}, \mathrm{CTLA}-4^{+}, \mathrm{LAG}-3^{+}$, and TIM- $3^{+}(\mathrm{n}=4-5$ mice/group). Absolute numbers are compared by student's unpaired t-test with Welch's correction, ${ }^{*} \mathrm{P}<0.05$. 
$\operatorname{lgG} \mathbf{b}$

A.

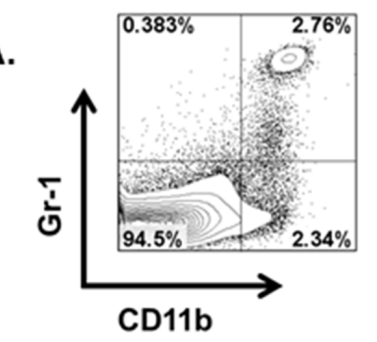

B.

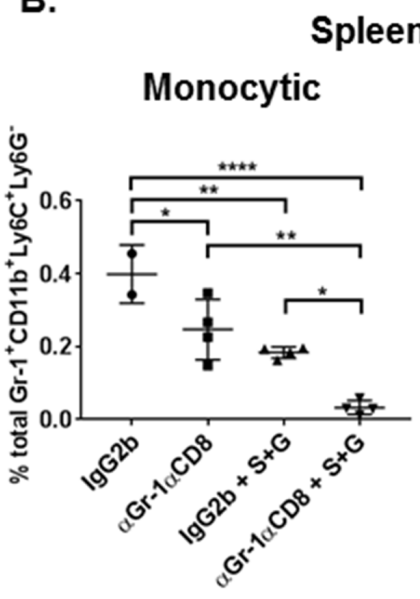

$\alpha \mathrm{Gr}-1 \alpha \mathrm{CD} 8$

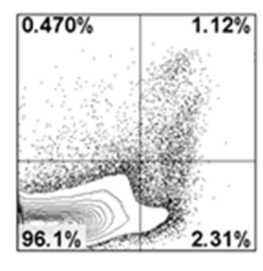

$\lg \mathbf{G} 2 \mathrm{~b}+\mathrm{S}+\mathbf{G}$

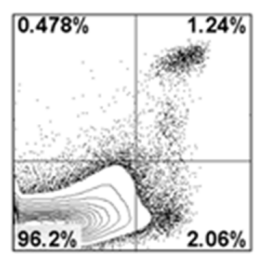

$\alpha \mathrm{Gr}-1 \alpha \mathrm{CD} 8+\mathrm{S}+\mathrm{G}$

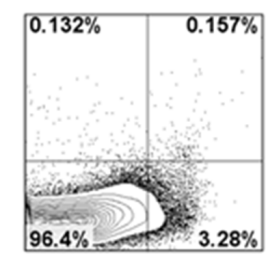

$\lg \mathbf{G} \mathbf{b}$

C.

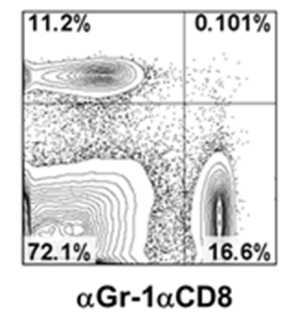

Granulocytic
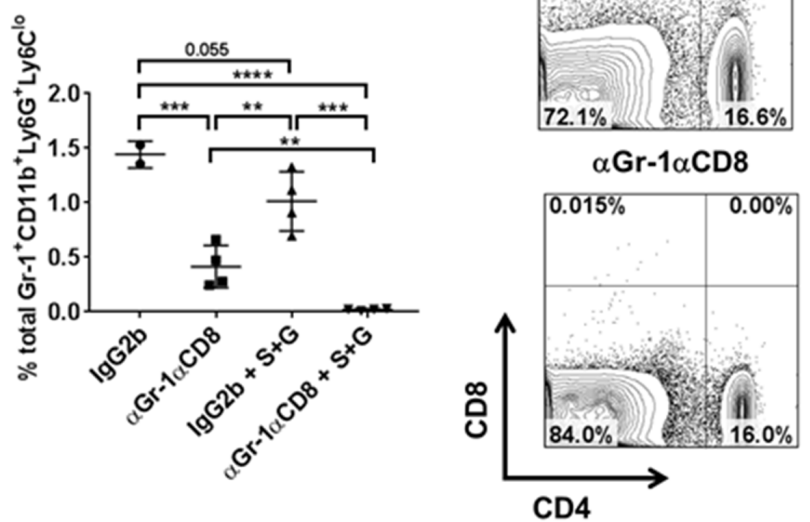

D.

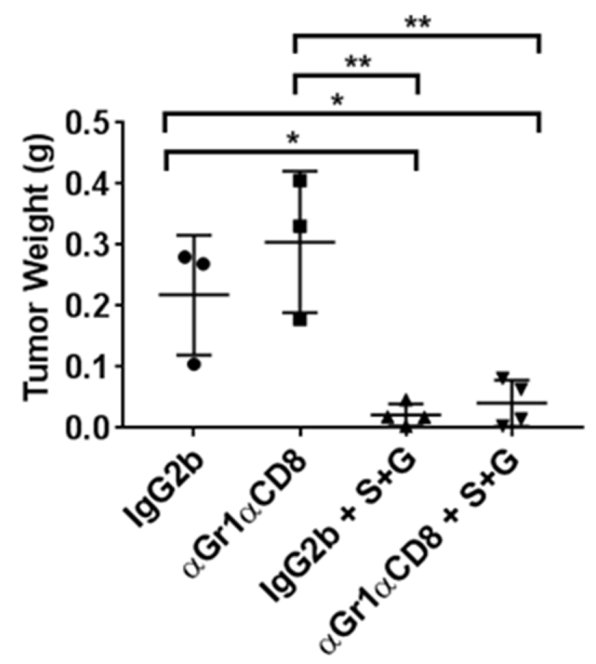

Figure 6: Both combination therapy and MDSC depletion reduce overall tumor burden and splenic MDSC subsets. On day-3 following tumor implant, WT mice ( $\mathrm{n}=3-4$ mice/group) were administered depleting antibodies (BioXCell) for Gr-1 and CD8a or IgG2b isotype control by i.p. injection. On days 4 and 7, one group of Gr-1 and CD8a depleted mice ( $\alpha \mathrm{Gr}-1 \alpha \mathrm{CD} 8)$ and $\operatorname{IgG} 2 \mathrm{~b}$ mice were also treated with combination therapy $(\mathrm{S}+\mathrm{G})$ by i.p. route. Mice were sacrificed on day- 9 when spleens and tumor nodules were collected. Spleens were prepared for flow cytometric analyses of $\mathrm{Gr}-1^{+} \mathrm{CD} 11 \mathrm{~b}^{+}$granulocytic and monocytic MDSCs as well as $\mathrm{CD} 8^{+}$and $\mathrm{CD} 4^{+} \mathrm{T}$ cells. A. FACS analyses of splenic tissue confirmed MDSC depletion in $\alpha \mathrm{Gr}-1 \alpha \mathrm{CD} 8$, combination therapy alone (IgG2b $+\mathrm{S}+\mathrm{G})$, and $\alpha \mathrm{Gr}-1 \alpha \mathrm{CD} 8$ $+\mathrm{S}+\mathrm{G}$ mice compared to isotype control (IgG2b). B. Within the spleen, total percentages of monocytic and granulocytic MDSCs were reduced in IgG2b $+\mathrm{S}+\mathrm{G}$ mice compared to isotype alone while $\alpha \mathrm{Gr}-1 \alpha \mathrm{CD} 8+\mathrm{S}+\mathrm{G}$ mice demonstrated a significant impairment of spleen MDSC subsets compared to both $\alpha \mathrm{Gr}-1 \alpha \mathrm{CD} 8$ and IgG2b $+\mathrm{S}+\mathrm{G}$ mice. Monocytic MDSC data are compared by one-way ANOVA with Tukey's post-test, ${ }^{*} \mathrm{P}<0.05,{ }^{*} * \mathrm{P}<0.005,{ }^{*} * * * \mathrm{P}<0.0001$. Granulocytic MDSCs are compared by one-way ANOVA with Tukey's post-test for IgG2 $b$ vs $\alpha \mathrm{Gr}-1 \alpha \mathrm{CD} 8, \alpha \mathrm{Gr}-1 \alpha \mathrm{CD} 8$ vs IgG2b $+\mathrm{S}+\mathrm{G}$, and IgG2b $+\mathrm{S}+\mathrm{G}$ vs $\alpha \mathrm{Gr}-1 \alpha \mathrm{CD} 8+\mathrm{S}+\mathrm{G},{ }^{*} * \mathrm{P}<0.01,{ }^{*} * \mathrm{P}<0.0005,{ }^{*} * * * \mathrm{P}<0.0001$, and by student's unpaired t-test for IgG2b vs IgG2b $+\mathrm{S}+\mathrm{G}$ and $\alpha \mathrm{Gr}-1 \alpha \mathrm{CD} 8$ vs $\alpha \mathrm{Gr}-1 \alpha \mathrm{CD} 8+\mathrm{S}+\mathrm{G}, * * \mathrm{P}<0.01$. C. Characterization of CD8 ${ }^{+}$ and $\mathrm{CD}^{+} \mathrm{T}$ lymphocytes in the spleen also confirmed the depletion of $\mathrm{CD} 8^{+} \mathrm{T}$ cells in $\alpha \mathrm{Gr}-1 \alpha \mathrm{CD} 8$ mice. D. Compared to IgG2b isotype control and $\alpha \mathrm{Gr}-1 \alpha \mathrm{CD} 8$ mice, the addition of $\mathrm{S}+\mathrm{G}$ significantly reduced tumor burden, respectively. Tumor weights are compared by oneway ANOVA with Tukey's post-test, $* \mathrm{P}<0.05, * *<0.005$. 
MDSCs contribute to immunosuppression in the TME and are associated with poor prognosis and tumor burden in cancer [30, 42]. MDSCs modulate arginine metabolism [42-44] and have recently been implicated in the regulation of Trp catabolism in the TME, generating Kyn which inhibits cytotoxic immune responses [4, 5, 34]. In our studies, MDSCs were the main contributors to IDO expression in the TME. Similarly, IDO expression in murine and human MDSCs has been attributed to tumor progression and immune escape [24-27, 32]. Our data demonstrate that IDO was expressed at similar levels in lung tumor nodules and purified tumor cells from both the WT and $\mathrm{IDO}^{-/}$tumor-bearing mice. Despite this, we found reduced tumor burden and MDSC infiltration in the IDO-deficient mice. This indicates that the decrease in tumor burden was attributable to IDO deficiency in TME-infiltrating cells rather than tumor cells themselves. Reduced MDSC infiltration in $\mathrm{IDO}^{-/}$mice suggests that IDO impairment within this non-tumor cell population impedes MDSC-driven tumor growth. This is consistent with the predominant IDO expression in tumor-associated MDSCs. These findings are substantiated by reduced GM-CSF in the tumor-bearing lungs of IDO-deficient mice, indicating that MDSC-promoting factors, including IDO and GM-CSF, support tumor growth. IDO deficiency in MDSCs abrogates these effects, replicated by the administration of combination treatment. The observation that IDO-deficient bone marrow-differentiated MDSCs are more apoptotic emphasizes the importance of IDO in sustaining MDSC proliferation. These data are consistent with another report that IDO deficiency mitigated lung tumor outgrowth, lesion formation, and MDSC suppressive function, improving overall survival in both KRAS-induced, spontaneous lung cancer and metastatic breast cancer models [6].

Previous studies investigating IDO signaling show that IDO regulates downstream GCN2 and mTOR pathways [10]. Some studies have examined the expression of IDO within immune cells following chemotherapy $[26,45,46]$. Our studies establish a relationship between IDO and nutrient-sensing mechanisms in the TME and further elucidate the alterations in cellular signaling within immune cells of the TME during IDO deficiency, by genetic and therapeutic strategies. Compared to WT controls, IDO-deficient MDSCs isolated from tumorbearing mice showed downregulated GCN2 and AMPK signaling, independent of mTOR activation. Taken together with our observations of enhanced apoptosis in IDO-deficient MDSCs, AMPK downregulation in the absence of IDO may influence the metabolic plasticity and ability of MDSCs to sustain the hostile TME. We also address here the reciprocal relationship between IDO and AMPK activation in the TME. Since the MDSCs are the main IDO contributors in the TME, reduction of IDO in MDSCs may influence AMPK activation in $\mathrm{CD} 8^{+} \mathrm{T}$ cells. This inverse relationship was observed in IDO-deficient
$\mathrm{CD}^{+} \mathrm{T}$ cells, with upregulation of GCN2 and AMPK activation, also independent of mTOR. Whether the absence of IDO in T cells mediates other compensatory downstream GCN2 activation pathways to alter metabolic signaling cues remains an area of further investigation. To overcome T cell inactivation induced by Trp depletion and Kyn accumulation, our studies show that effector T cells switch to alternate bioenergetics mechanisms to maintain survival in a nutrient-depleted TME. A regulatory role for AMPK is justified as it acts as a major regulatory kinase governing metabolic plasticity, survival, and memory formation of $\mathrm{T}$ cells during nutrient limitation [36, 37]. Enhanced activation of this pathway can improve the cytotoxicity and lifespan of these cells, potentially impeding continued tumor outgrowth. Additionally, the reduced infiltration of MDSCs resulting in reduced oxidative stress will decrease immunosuppression and promote expansion of effector $\mathrm{CD}^{+} \mathrm{T}$ cells shifting the balance in favor of anti-tumor immunity.

$\mathrm{CD}^{+}$and $\mathrm{CD}^{+} \mathrm{T}$ cells from spleens of $\mathrm{IDO}^{-/}$ mice exhibit reduced $\mathrm{PD}-1^{\mathrm{hi}}$ cell surface expression, corresponding to less $\mathrm{T}$ cell exhaustion. Tumor-derived $\mathrm{IDO}^{-/} \mathrm{CD}^{+} \mathrm{T}$ cells also demonstrate increased lactate and IFN- $\gamma$ production. This reversal of $\mathrm{T}$ cell exhaustion may contribute to the tumor burden reduction in $\mathrm{IDO}^{-/}$mice. These findings are especially pertinent as IDO has been shown to be a resistance mechanism that can impede the efficacy of checkpoint blockade therapies [39]. We observed no discernable difference in bioenergetics signaling pathways within tumor cells, suggesting that altered metabolic pathways in IDO-deficient MDSCs and $\mathrm{CD}^{+} \mathrm{T}$ cells keep tumor progression and metabolism in check. These results represent a novel finding that, in the absence of IDO within immune cells in the TME, AMPK functions as a key regulator of cellular metabolism.

We have also investigated the tumor-immune cross talk in the TME following treatment with our IDOinhibiting combination therapy. The direct targeting of IDO in both LLCs and MDSCs led to the activation of mTOR (Trp sufficiency) signaling in $\mathrm{CD}^{+} \mathrm{T}$ cells leading to enhanced IFN- $\gamma$ and lactate production in $\mathrm{T}$ cells. Importantly, when Trp sufficiency signal was activated in $\mathrm{CD}^{+} \mathrm{T}$ cells, we did not see a significant activation of AMPK, suggesting that mTOR activation was sufficient to enhance the effector function of the $\mathrm{CD}^{+} \mathrm{T}$ cells. We confirmed that combination therapy can directly impair tumor burden in the absence of MDSCs and $\mathrm{CD}^{+} \mathrm{T}$ cells suggesting that combination therapy has direct tumor-killing effects which may potentiate the efficacy of this therapy.

The expression of IDO has been shown to interfere with the efficiency of immunotherapies, including antiCTLA-4, anti-PD-1/PD-L1, and anti-GITR [39]. When anti-PD-1/PD-L1 therapy was administered to $\mathrm{IDO}^{-/}$mice harboring B16F10 melanoma, they survived significantly longer compared to WT [39]. In our studies, tumor-bearing $\mathrm{IDO}^{-/}$mice have fewer PD- ${ }^{\text {hi }} \mathrm{T}$ cells that may reduce 
PD-1/PD-L1 interaction, prompting a more robust immune response. This is particularly interesting as PD-L1 has been identified to play a pivotal role in licensing glycolytic metabolism of tumor cells via AKT/mTOR, which limits nutrients needed for T cell survival and function [47].

Checkpoint blockade agents have been ineffective as single agents in IDO-overexpressing cancer models because they require a functional immune response to be elicited from tumor-residing $\mathrm{CD}^{+} \mathrm{T}$ cells $[39,48]$. Many cancer patients diagnosed with late stage cancers exhibit $\mathrm{CD} 8^{+} \mathrm{T}$ cell hypo-responsiveness, which is primarily driven by nutrient competition between tumor and immune cells, limiting response to these kinds of therapies [47]. A study using human cancer cell lines has also identified IDO as a resistance mechanism to chemotherapeutics, including gemcitabine, making IDO a viable target [49]. Our combination therapy is advantageous by targeting MDSCs expressing IDO and enhancing $\mathrm{CD}^{+} \mathrm{T}$ cell metabolism necessary to achieve anti-tumor immunity, thus potentially making it successful without the use of additional IDO inhibitors.

From a clinical standpoint, the complex composition of the TME should not be overlooked and must be leveraged to enhance the efficacy of novel compounds and multi-modal therapies. As treatment regimens are becoming more individualized in the clinic, procedures to measure whether these agents can be directly associated with downregulation of IDO in both tumor and immune cells are warranted. Additionally, SOD mimetics may be used as adjuvants to MDSC-depleting therapies in order to directly target IDO in these cells.

Although we do not address the contribution of other cell types present in the heterogeneous TME, this study demonstrates the importance of cell-specific signaling that may influence cell-to-cell communication and direct metabolic instructions within the tumor. Based on these findings, we conclude that IDO, mTOR, and AMPK signaling pathways are differentially regulated in a cell-specific manner. In IDO-deficient mice, mTOR appears to be controlled independently of AMPK activation and dictates a new role for IDO in modulating this metabolic pathway. Importantly, combination therapy with gemcitabine and a SOD mimetic alters IDO, GCN2, and mTOR activation in MDSCs and LLCs in the TME, which can improve glycolytic metabolism and function of $\mathrm{CD}^{+} \mathrm{T}$ cells in vivo (Figure 7). Our depletion studies in mice also confirm an advantage of this combination therapy in directly diminishing tumor burden, even in the absence of both MDSCs and $\mathrm{CD}^{+} \mathrm{T}$ cells. These results

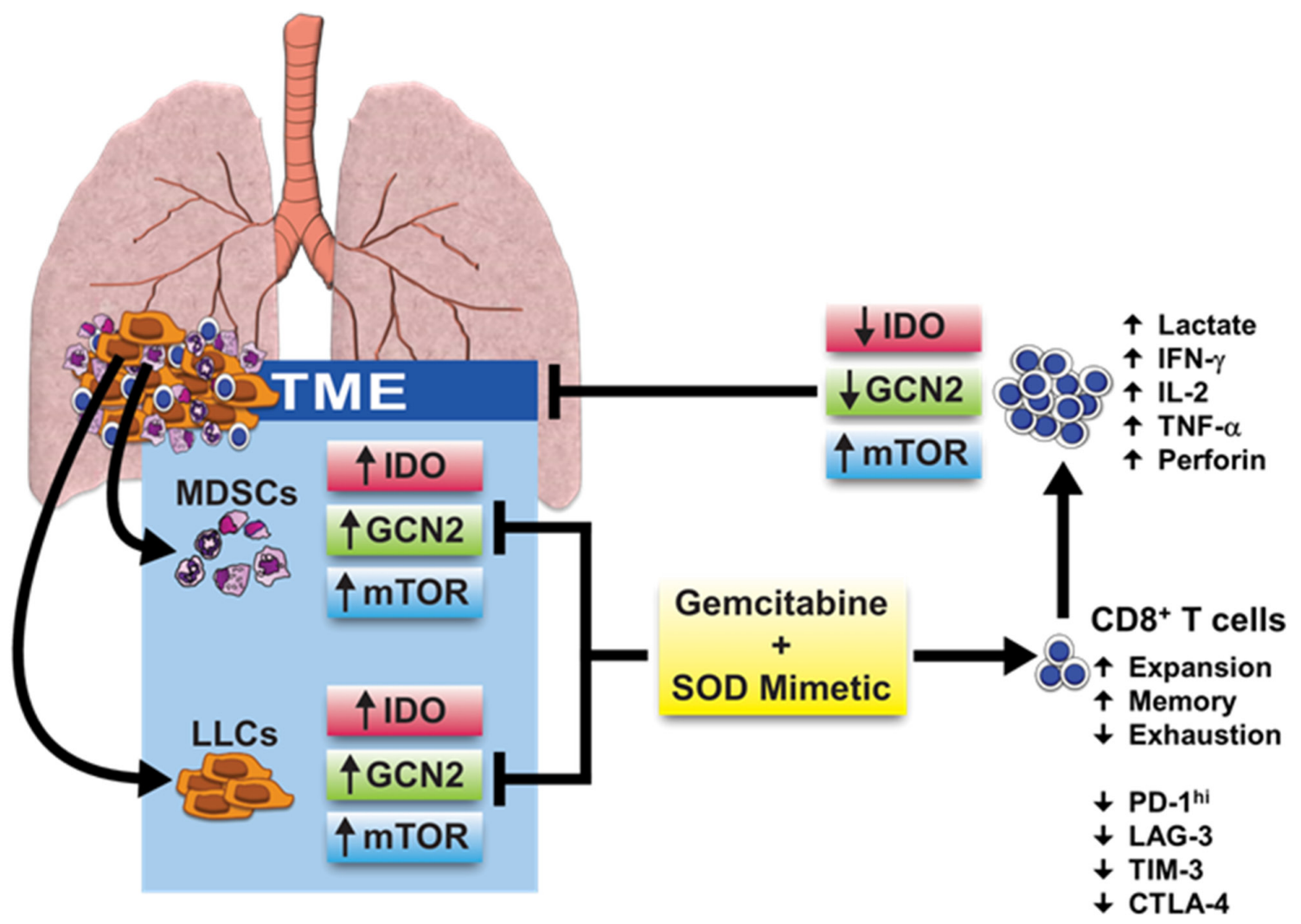

Figure 7: Effects of combination therapy on cellular signaling pathways and metabolic reprogramming in the TME. A combination therapy of gemcitabine and a SOD mimetic inhibits IDO, GCN2, and mTOR pathway activation in IDO-expressing MDSCs and LLCs. This reverses immune suppression, reduces anti-tumor T cell exhaustion, and rescues mTOR activation in CD8 $8^{+} \mathrm{T}$ cells enabling their expansion and reprogramming towards a glycolytic state. Phosphorylation of S6 in $\mathrm{CD} 8^{+} \mathrm{T}$ cells licenses IFN- $\gamma$ production necessary to elicit cytotoxic effects, diminishing tumor burden and restoring anti-tumor immunity. 
demonstrate the novelty of this therapy, especially as IDO inhibitors and immune-modulating therapies are becoming more translationally relevant in the clinic $[11,50]$. Overall, this study highlights the importance of metabolic cellular signaling and establishes a potential mechanism for a combination therapy of gemcitabine and a SOD mimetic that targets IDO in MDSCs and tumor cells to promote anti-tumor immunity against lung cancer.

\section{MATERIALS AND METHODS}

\section{Cell culture}

Mouse-specific Lewis lung carcinoma cells (LLCs) (ATCC) were propagated in Dulbecco's Modified Eagle Medium (DMEM) supplemented with 10\% fetal bovine serum, $1 \mathrm{mM}$ sodium pyruvate, $2 \mathrm{mM}$ L-glutamine, $10 \mu \mathrm{g} / \mathrm{ml}$ penicillin-streptomycin and $0.1 \mathrm{mM}$ nonessential amino acids (Life Technologies, Carlsbad, CA) as previously described [15]. LLCs were authenticated following ATCC guidelines based on morphology (rounded-loosely attached or floating), viability, recovery, and growth, and were confirmed one month before use in the experiments described. For in vitro experiments, LLCs were seeded in 6-well plates until 70-80\% confluent then treated with fresh media containing 0-100 ng of recombinant mouse IFN- $\gamma$ (eBioscience).

\section{Syngeneic mouse model of lung cancer}

6-8 week old C57BL6 (Frederick Cancer Research and Development Center, MD) and B6.129-Ido1/J (Jackson Labs) $\left(\mathrm{IDO}^{-/}\right)$mice were injected with LLCs via intracardiac (i.c.) or intravenous (i.v.) route into isoflurane (Fisher) anesthetized mice, as previously described [15]. C57BL6 mice were treated by intraperitoneal route (i.p.) with superoxide dismutase mimetic (SOD) (10 $\mathrm{mg} / \mathrm{kg}) \quad(\mathrm{Mn}(\mathrm{III})$ tetrakis(1-methyl-4-pyridyl)porphyrin (MnTMPyP - Calbiochem), EMD Millipore, cat. no. 475872) [51] and/or gemcitabine (GEM) (60 mg/kg) (Sigma-Aldrich) at Days 3, 7, and 10 post-i.c. injection. For experiments involving the IDO inhibitor, 1-methylD-tryptophan (D1MT) (Sigma-Aldrich), $1.5 \mathrm{mg} / 150 \mathrm{ml} /$ mouse solutions were prepared freshly by dissolving D1MT in $0.1 \mathrm{~N} \mathrm{NaOH}$ then adjusting the $\mathrm{pH}$ to 7 with $0.1 \mathrm{~N} \mathrm{HCl}$. Injections were administered by i.p. route in the morning and again in the afternoon for a total of 3 $\mathrm{mg} / \mathrm{mouse} /$ day of D1MT on days-3, 5, and 8 post-tumor implant. Mice were monitored and euthanized following UAB IACUC guidelines and protocols. Serum was collected post-exsanguination and this was followed by i.c. lung perfusion with $1 \mathrm{X}$ PBS prior to removing lung tissues. Nodules from the harvested tumor masses, lung surface, and chest cavity were dissected then individually counted. Tumor weights were determined by pooling all nodules prior to tissue digestion.

\section{Western blotting}

Tissue homogenates from lung, tumor, spleen, and sorted cell lysates were prepared in either PBS or RIPA buffer containing protease inhibitors. Samples were normalized for total protein (Pierce BCA Protein Assay Kit, Thermo Scientific) and run on 4-15\% Mini-Protean TGX (Bio-Rad) or on 10\% SDS-PAGE gels. Gels were transferred to $0.45 \mu \mathrm{m}$ Immobilon-P PVDF membranes (EMD Millipore), blocked in either 5\% non-fat dry milk (Lab Scientific) or Bovine Serum Albumin (BSA) (Fisher Scientific), and probed with antibodies overnight at $4^{\circ} \mathrm{C}$. Blots were incubated for $1 \mathrm{hr}$ at room temperature in secondary anti-rabbit or anti-mouse HRP-conjugated antibodies (Promega) prior to imaging with Luminol Reagent (Santa Cruz Biotechnology, Inc. and Millipore) and Kodak X-ray film (Z\&Z Medical, Inc.). Antibodies used in immunoblots were peIF2 $\alpha$ Ser51, GCN2, pLKB1 Ser428 (C67A3), pAMPK Thr172 (40H9), AMPKa (total AMPK) (Cell Signaling), pS6 Ser240/Ser244, pPFKFB2 Ser466, IDO Clone 10.1 (EMD Millipore, LifeSpan BioSciences, Inc.), IDO2 (Rockland Immunochemicals, Inc.), TDO2 (clone E-14, Santa Cruz), and actin (SigmaAldrich) at manufacturers' recommended dilutions.

\section{Flow cytometry and cell sorting}

As described previously [15], tumor tissues were minced on ice in serum-free Iscove's Dulbecco's Modified Eagle Medium (IDMEM) (Corning) and then digested in serum-free IDMEM supplemented with 2 $\mathrm{mg} / \mathrm{ml}$ of collagenase $\mathrm{B}$ (Roche) and $0.02 \mathrm{mg} / \mathrm{ml}$ of deoxyribonuclease I from bovine pancreas (Sigma) at $37^{\circ} \mathrm{C}$ for $30 \mathrm{~min}$. After digestion, suspensions were neutralized with sterile IDMEM containing 10\% fetal bovine serum (FBS) (Peak Serum) filtered through 0.45 $\mathrm{mm}$ strainers. ACK lysis buffer (Quality Biological, Inc.) was added to cell pellets to lyse any red blood cells present and washed with PBS. Spleen cells were extracted by cutting the capsule in half and scratching out the pulp into a dish containing cold PBS. Tumor and spleen cell suspensions were filtered, treated with ACK, and incubated on ice for $30 \mathrm{~min}$ in 3\% BSA in PBS containing purified rat anti-mouse CD16/CD32 (Clone 2.4G2) (BD Pharmingen) to block murine $\mathrm{F}_{\mathrm{c}}$ receptors. Cells were then stained with Gr-1 PE/APC (Clone RB6-8C5), Ly6C PerCPCy5.5 (HK1.4), CD8a FITC/APC (53-6.7), CD45 PE (30-F11), CD4 PECy7 (GK1.5), CD279/PD-1 PerCP-eFluor710 (J43), CTLA-4 (UC10-4B9), LAG-3 (C9B7W), TIM-3 (8B.2C12), CD11b APCCy7 (M1/70), and Ly6G FITC (1A8) (BD Pharmingen) antibodies for an additional $30 \mathrm{~min}$ on ice protected from light. Cells were washed with PBS prior to flow cytometry on BD LSR-II or sorting on BD FACS Aria III cytometer (UAB Flow Cytometry Core Facility). Additionally, intracellular staining was performed on spleen and tumor $\mathrm{CD}^{+} \mathrm{T}$ 
cells for IL-2 (JES6-5H4), TNF- $\alpha$ (MP6-XT22), perforin (eBioOMAK-D) (eBioscience), and IFN- $\gamma$ (XMG1.2) (BD Pharmingen). Cells were incubated in stimulating RPMI media containing Phorbol 12-myristate 13-acetate, or PMA, (0.1 $\mathrm{mg} / \mathrm{ml}$, Sigma), ionomycin $(1 \mathrm{mg} / \mathrm{ml}$, Sigma), and a 1:1000 dilution of Golgistop/Golgiplug (BD Biosciences). Following stimulation, cells were permeabilized using the BD cytofix/cytoperm kit (BD Biosciences) then stained for CD8 as well as intracellular cytokine markers. Data were analyzed using FlowJo software (version 7.6.5). For FACS purification, tumor cell suspensions were stained with antibodies recognizing CD45 (also known as leukocyte common antigen), Gr-1, CD11b, and CD8. Non-hematopoietic cells, representing LLC tumor cells, were derived from the $\mathrm{CD}^{4} 5^{-}$population. Within the same antibody cocktail, hematopoietic MDSCs were isolated from $\mathrm{Gr}-1^{+} \mathrm{CD} 11 \mathrm{~b}^{+}$population within the $\mathrm{CD} 5^{+}$cell gate. Similarly, CD8 ${ }^{+} \mathrm{T}$ cells were purified from the $\mathrm{CD}^{+}$cells within the $\mathrm{CD} 45^{+}$cell gate.

\section{Differentiation of bone marrow MDSCs and apoptosis quantitation by flow cytometry}

Femur and tibia bones were pooled from naïve WT and $\mathrm{IDO}^{-}$mice and whole bone marrow suspensions were cultured in MDSC-differentiating medium, as previously described [52]. Cells were cultured in 6-well plates in complete RPMI media (described below) at a concentration of $5 \times 10^{6}$ cells $/ \mathrm{ml}, 1 \mathrm{mg} / \mathrm{ml}$ lipopolysaccharide (LPS) (from Escherichia coli 0111:B4, Sigma), and $10 \mathrm{ng} / \mathrm{ml}$ recombinant mouse granulocyte-macrophage colonystimulating factor (GM-CSF) (eBioscience). After four days of incubation at $37^{\circ} \mathrm{C}$, non-adherent cells were isolated and re-stimulated for another four days until samples were analyzed by flow cytometry. As described above, cells were first stained with Gr-1 APC and CD11b APCCy7 antibodies, washed in cold PBS, and then stained for Annexin V FITC and PI according to the manufacturer's protocol from the FITC Annexin V apoptosis detection kit I (BD Pharmingen).

\section{Ex vivo expansion of $\mathrm{CD8}^{+} \mathrm{T}$ cells}

Following tumor tissue digestion, $\mathrm{CD} 45^{+} \mathrm{CD} 8^{+}$ $\mathrm{T}$ cells were isolated by FACS. Cells were expanded $e x$ vivo, as described before [15]. CD8 ${ }^{+} \mathrm{T}$ cells were cultured at $5 \times 10^{5}$ cells per well in a U-bottom 96-well plate in RPMI 1640 media (Corning) containing 10\% fetal bovine serum (FBS) (Peak Serum), 2 mM L-glutamine (Fisher), $1 \mathrm{mM}$ sodium pyruvate (Life Technologies), $0.1 \mathrm{mM}$ non-essential amino acids (Life Technologies), $10 \mathrm{mg} / \mathrm{ml}$ penicillin-streptomycin-amphotericin B (Fisher), $50 \mathrm{mM}$ 2-mercaptoethanol (Sigma), $6.25 \mathrm{mg} / \mathrm{ml}$ recombinant mouse Interleukin-2 (IL-2) (eBioscience), $4 \mathrm{mg} / \mathrm{ml}$ purified hamster anti-mouse CD28 (clone 37.51) (BD Pharmingen), and $0.75 \mathrm{mg} / \mathrm{ml}$ purified anti-mouse CD3e (clone 145-2C11) (eBioscience). $\mathrm{CD}^{+} \mathrm{T}$ cells were expanded ex vivo with stimulating antibodies and IL-2 every four days for three-four passages until a visible cell pellet could be collected for lysate. Cell pellets were washed in 1X PBS prior to cell lysis in cold, 1X RIPA buffer followed by sonication on ice. Total protein was determined as described above.

\section{Lactate assay}

Cell pellets were washed in PBS and stored at $-80^{\circ} \mathrm{C}$ until use. Cell pellets were directly homogenized in lactate assay buffer and cleared by centrifugation. A lactate assay kit (BioVision, Inc.) was used to detect lactate concentrations within cell pellets or $\mathrm{T}$ cell supernatants.

\section{Enzyme linked immunosorbent assays (ELISAs)}

Lung homogenates were prepared on ice in sterile PBS using a glass pestle tissue grinder and cleared by centrifugation. Cleared homogenates, as well as culture supernatants, were stored at $-80^{\circ} \mathrm{C}$ until use. ELISA kits for mouse GM-CSF and IFN- $\gamma$ were purchased from eBioscience.

\section{IDO enzymatic activity assay}

An IDO enzymatic activity was performed using a protocol adapted from previously described methods $[53,54]$. Murine samples used in the IDO activity assays were prepared in Dulbecco's Phosphate Buffered Saline (DPBS) (Fisher) containing protease inhibitors followed by sonication. 2X IDO reaction buffer $(200 \mathrm{mg} / \mathrm{ml}$ catalase from bovine liver (Sigma), $800 \mathrm{mM}$ L-tryptophan (Sigma), $100 \mathrm{mM}$ DPBS, $40 \mathrm{mM}$ L-ascorbic acid (Sigma), $20 \mathrm{mM}$ methylene blue (Fisher), with and without tryptophan, was added to samples that were normalized for total protein by BCA assay. Samples were incubated at $37^{\circ} \mathrm{C}$ for $30 \mathrm{~min}$ and the reaction was stopped with $30 \%$ trichloroacetic acid (TCA) (Sigma). Samples were incubated again at $52^{\circ} \mathrm{C}$ for $30 \mathrm{~min}$ followed by centrifugation $\left(5 \mathrm{~min}, 10,000 \mathrm{rpm}, 4^{\circ} \mathrm{C}\right.$ ). Supernatants were used for spectrophotometric analyses by the addition of an equal amount of Ehrlich's Solution (Sigma). Samples were read at an absorbance of $480 \mathrm{~nm}$ and values were calculated based on a standard curve of L-Kynurenine (Sigma) from 0-30,000 mM. Final IDO activity values were determined by taking the difference between samples without tryptophan-containing IDO reaction buffer and those receiving tryptophan-containing IDO reaction buffer.

\section{Depletion experiments}

LLC-implanted WT mice were injected i.p. on day-3 following tumor implant with $250 \mathrm{mg} / 100 \mathrm{ml} /$ mouse of IgG2b isotype control (clone LTF-2), anti-Gr-1 (clone RB6-8C5), or anti-CD8a (clone 2.43) InVivoPlus antibodies purchased from BioXCell. Mice were then treated with individual or combination therapy, as described above, before sacrificing on day- 9 . 


\section{Statistical analyses}

Student's t-test (Unpaired, with or without Welch's correction), multiple t-tests (Holm-Sidak), one-way ANOVA, and two-way ANOVA were used for statistical comparisons. ANOVA post-hoc analyses were conducted by implementing Dunnett's and Tukey's multiple comparisons test along with adjusted $\mathrm{P}$ values. All graphs represent Mean $\pm \mathrm{SD}$. Comparisons between WT and IDO - were evaluated by an unpaired student's t-test without Welch's correction unless otherwise stated. Results were calculated using GraphPad Prism 6.05 and Microsoft Excel 2010.

\section{ACKNOWLEDGMENTS}

We appreciate the feedback and guidance on this project provided by Drs. Theresa Strong, Douglas Hurst, and Donald Buchsbaum at UAB. We also acknowledge Marion Spell and Enid Keyser at the UAB Flow Cytometry Core Facilities for their technical assistance in acquiring sorted cell samples. We thank Dr. Chad Steele at UAB for use of his laboratory's 96well plate reader.

\section{CONFLICTS OF INTEREST}

There are no financial conflicts of interest for any of the authors listed.

\section{GRANT SUPPORT}

Funding was provided by NCI CA 13148-39 UAB CCC CDGP and the American Cancer Society Institutional Research Grant Award ID: IRG-60-00153-IRG awarded to J.S.D. and R01CA184770 awarded to S.P.

\section{REFERENCES}

1. Platten M, Wick W and Van den Eynde BJ. Tryptophan catabolism in cancer: beyond IDO and tryptophan depletion. Cancer research. 2012; 72:5435-5440.

2. Muller AJ, DuHadaway JB, Chang MY, Ramalingam A, Sutanto-Ward E, Boulden J, Soler AP, Mandik-Nayak L, Gilmour SK and Prendergast GC. Non-hematopoietic expression of IDO is integrally required for inflammatory tumor promotion. Cancer immunology, immunotherapy. 2010; 59:1655-1663.

3. Munn DH and Mellor AL. Indoleamine 2,3-dioxygenase and tumor-induced tolerance. The Journal of clinical investigation. 2007; 117:1147-1154.

4. Schrocksnadel K, Wirleitner B, Winkler C and Fuchs D. Monitoring tryptophan metabolism in chronic immune activation. Clinica chimica acta. 2006; 364:82-90.
5. Kurz K, Schroecksnadel S, Weiss G and Fuchs D. Association between increased tryptophan degradation and depression in cancer patients. Current opinion in clinical nutrition and metabolic care. 2011; 14:49-56.

6. Smith C, Chang MY, Parker KH, Beury DW, DuHadaway JB, Flick HE, Boulden J, Sutanto-Ward E, Soler AP, Laury-Kleintop LD, Mandik-Nayak L, Metz R, OstrandRosenberg S, Prendergast GC and Muller AJ. IDO is a nodal pathogenic driver of lung cancer and metastasis development. Cancer discovery. 2012; 2:722-735.

7. Wang $\mathrm{R}$ and Green DR. Metabolic reprogramming and metabolic dependency in T cells. Immunological reviews. 2012; 249:14-26.

8. Sharma P and Allison JP. The future of immune checkpoint therapy. Science (New York, NY). 2015; 348:56-61.

9. Vanneman M and Dranoff G. Combining immunotherapy and targeted therapies in cancer treatment. Nature reviews Cancer. 2012; 12:237-251.

10. Metz R, Rust S, Duhadaway JB, Mautino MR, Munn DH, Vahanian NN, Link CJ and Prendergast GC. IDO inhibits a tryptophan sufficiency signal that stimulates mTOR: A novel IDO effector pathway targeted by D-1-methyltryptophan. Oncoimmunology. 2012; 1:1460-1468.

11. Prendergast GC, Smith C, Thomas S, Mandik-Nayak L, Laury-Kleintop L, Metz R and Muller AJ. Indoleamine 2,3-dioxygenase pathways of pathogenic inflammation and immune escape in cancer. Cancer immunology, immunotherapy. 2014; 63:721-735.

12. Inoki K, Kim J and Guan KL. AMPK and mTOR in cellular energy homeostasis and drug targets. Annual review of pharmacology and toxicology. 2012; 52:381-400.

13. Magnuson B, Ekim B and Fingar DC. Regulation and function of ribosomal protein S6 kinase (S6K) within mTOR signalling networks. The Biochemical journal. 2012; 441:1-21.

14. Harding HP, Zhang Y, Zeng H, Novoa I, Lu PD, Calfon M, Sadri N, Yun C, Popko B, Paules R, Stojdl DF, Bell JC, Hettmann T, Leiden JM and Ron D. An integrated stress response regulates amino acid metabolism and resistance to oxidative stress. Molecular cell. 2003; 11:619-633.

15. Sawant A, Schafer CC, Jin TH, Zmijewski J, Tse HM, Roth J, Sun Z, Siegal GP, Thannickal VJ, Grant SC, Ponnazhagan $\mathrm{S}$ and Deshane JS. Enhancement of antitumor immunity in lung cancer by targeting myeloid-derived suppressor cell pathways. Cancer research. 2013; 73:6609-6620.

16. Wesolowski R, Markowitz J and Carson WE, 3rd. Myeloid derived suppressor cells - a new therapeutic target in the treatment of cancer. Journal for immunotherapy of cancer. 2013; 1:10.

17. Sharma MD, Baban B, Chandler P, Hou DY, Singh N, Yagita H, Azuma M, Blazar BR, Mellor AL and Munn DH. Plasmacytoid dendritic cells from mouse tumor-draining lymph nodes directly activate mature Tregs via indoleamine 2,3-dioxygenase. The Journal of clinical investigation. 2007; 117:2570-2582. 
18. Luo Z, Zang M and Guo W. AMPK as a metabolic tumor suppressor: control of metabolism and cell growth. Future oncology (London, England). 2010; 6:457-470.

19. Li W, Saud SM, Young MR, Chen G and Hua B. Targeting AMPK for cancer prevention and treatment. Oncotarget. 2015; 6:7365-7378. doi:10.18632/oncotarget.3629.

20. Blagih J, Coulombe F, Vincent EE, Dupuy F, GaliciaVazquez G, Yurchenko E, Raissi TC, van der Windt GJ, Viollet B, Pearce EL, Pelletier J, Piccirillo CA, Krawczyk CM, Divangahi M and Jones RG. The energy sensor AMPK regulates $\mathrm{T}$ cell metabolic adaptation and effector responses in vivo. Immunity. 2015; 42:41-54.

21. Ros S and Schulze A. Balancing glycolytic flux: the role of 6-phosphofructo-2-kinase/fructose 2,6-bisphosphatases in cancer metabolism. Cancer \& metabolism. 2013; 1:8.

22. Faubert B, Vincent EE, Poffenberger MC and Jones RG. The AMP-activated protein kinase (AMPK) and cancer: many faces of a metabolic regulator. Cancer letters. 2015; 356:165-170.

23. Rolf J, Zarrouk M, Finlay DK, Foretz M, Viollet B and Cantrell DA. AMPKalpha1: a glucose sensor that controls CD8 T-cell memory. European journal of immunology. 2013; 43:889-896.

24. Yu J, Du W, Yan F, Wang Y, Li H, Cao S, Yu W, Shen C, Liu J and Ren X. Myeloid-derived suppressor cells suppress antitumor immune responses through IDO expression and correlate with lymph node metastasis in patients with breast cancer. Journal of immunology (Baltimore, Md : 1950). 2013; 190:3783-3797.

25. Platten M, von Knebel Doeberitz N, Oezen I, Wick W and Ochs K. Cancer Immunotherapy by Targeting IDO1/TDO and Their Downstream Effectors. Front Immunol. 2014; 5:673.

26. Alizadeh D, Trad M, Hanke NT, Larmonier CB, Janikashvili N, Bonnotte B, Katsanis E and Larmonier N. Doxorubicin eliminates myeloid-derived suppressor cells and enhances the efficacy of adoptive T-cell transfer in breast cancer. Cancer research. 2014; 74:104-118.

27. Jitschin R, Braun M, Buttner M, Dettmer-Wilde K, Bricks J, Berger J, Eckart MJ, Krause SW, Oefner PJ, Le Blanc K, Mackensen A and Mougiakakos D. CLL-cells induce IDOhi CD14+HLA-DRlo myeloid-derived suppressor cells that inhibit T-cell responses and promote TRegs. Blood. 2014; 124:750-760.

28. Zaidi MR and Merlino G. The two faces of interferongamma in cancer. Clinical cancer research. 2011; 17:6118-6124.

29. Bayne LJ, Beatty GL, Jhala N, Clark CE, Rhim AD, Stanger $\mathrm{BZ}$ and Vonderheide RH. Tumor-derived granulocytemacrophage colony-stimulating factor regulates myeloid inflammation and $\mathrm{T}$ cell immunity in pancreatic cancer. Cancer cell. 2012; 21:822-835.

30. Talmadge JE and Gabrilovich DI. History of myeloid-derived suppressor cells. Nature reviews Cancer. 2013; 13:739-752.
31. Kao J, Ko EC, Eisenstein S, Sikora AG, Fu S and Chen SH. Targeting immune suppressing myeloid-derived suppressor cells in oncology. Critical reviews in oncology/hematology. 2011; 77:12-19.

32. Monu NR and Frey AB. Myeloid-derived suppressor cells and anti-tumor T cells: a complex relationship. Immunological investigations. 2012; 41:595-613.

33. Mellor AL and Munn DH. IDO expression by dendritic cells: tolerance and tryptophan catabolism. Nature reviews Immunology. 2004; 4:762-774.

34. Murakami Y, Hoshi M, Imamura Y, Arioka Y, Yamamoto $\mathrm{Y}$ and Saito K. Remarkable role of indoleamine 2,3-dioxygenase and tryptophan metabolites in infectious diseases: potential role in macrophage-mediated inflammatory diseases. Mediators of inflammation. 2013; 2013:391984.

35. Rao E, Zhang Y, Zhu G, Hao J, Persson XM, Egilmez NK, Suttles J and Li B. Deficiency of AMPK in CD8+ T cells suppresses their anti-tumor function by inducing protein phosphatase-mediated cell death. Oncotarget. 2015; 6:79447958. doi:10.18632/oncotarget.3501.

36. Araki K and Ahmed R. AMPK: a metabolic switch for CD8+ T-cell memory. European journal of immunology. 2013; 43:878-881.

37. Yang $\mathrm{K}$ and Chi H. AMPK helps T cells survive nutrient starvation. Immunity. 2015; 42:4-6.

38. Hanahan D and Weinberg RA. Hallmarks of cancer: the next generation. Cell. 2011; 144:646-674.

39. Holmgaard RB, Zamarin D, Munn DH, Wolchok JD and Allison JP. Indoleamine 2,3-dioxygenase is a critical resistance mechanism in antitumor $\mathrm{T}$ cell immunotherapy targeting CTLA-4. The Journal of experimental medicine. 2013; 210:1389-1402.

40. Fallarino F, Grohmann U and Puccetti P. Indoleamine 2,3-dioxygenase: from catalyst to signaling function. European journal of immunology. 2012; 42:1932-1937.

41. Ninomiya S, Narala N, Huye L, Yagyu S, Savoldo B, Dotti G, Heslop HE, Brenner MK, Rooney CM and Ramos CA. Tumor indoleamine 2,3-dioxygenase (IDO) inhibits CD19CAR T cells and is downregulated by lymphodepleting drugs. Blood. 2015; 125:3905-3916.

42. Khaled YS, Ammori BJ and Elkord E. Myeloid-derived suppressor cells in cancer: recent progress and prospects. Immunology and cell biology. 2013; 91:493-502.

43. Raber P, Ochoa AC and Rodriguez PC. Metabolism of L-arginine by myeloid-derived suppressor cells in cancer: mechanisms of $\mathrm{T}$ cell suppression and therapeutic perspectives. Immunological investigations. 2012; 41:614-634.

44. Gabrilovich DI, Ostrand-Rosenberg S and Bronte V. Coordinated regulation of myeloid cells by tumours. Nature reviews Immunology. 2012; 12:253-268.

45. Sim SH, Ahn YO, Yoon J, Kim TM, Lee SH, Kim DW and Heo DS. Influence of chemotherapy on nitric oxide synthase, indole-amine-2,3-dioxygenase and CD124 
expression in granulocytes and monocytes of non-small cell lung cancer. Cancer science. 2012; 103:155-160.

46. Muller AJ, DuHadaway JB, Donover PS, SutantoWard E and Prendergast GC. Inhibition of indoleamine 2,3-dioxygenase, an immunoregulatory target of the cancer suppression gene Bin1, potentiates cancer chemotherapy. Nature medicine. 2005; 11:312-319.

47. Chang CH, Qiu J, O’Sullivan D, Buck MD, Noguchi T, Curtis JD, Chen Q, Gindin M, Gubin MM, van der Windt GJ, Tonc E, Schreiber RD, Pearce EJ and Pearce EL. Metabolic Competition in the Tumor Microenvironment Is a Driver of Cancer Progression. Cell. 2015; 162:1229-1241.

48. Spranger S, Koblish HK, Horton B, Scherle PA, Newton $\mathrm{R}$ and Gajewski TF. Mechanism of tumor rejection with doublets of CTLA-4, PD-1/PD-L1, or IDO blockade involves restored IL-2 production and proliferation of CD8(+) T cells directly within the tumor microenvironment. Journal for immunotherapy of cancer. 2014; 2:3.

49. Maleki Vareki S, Chen D, Di Cresce C, Ferguson PJ, Figueredo R, Pampillo M, Rytelewski M, Vincent M, Min W, Zheng $\mathrm{X}$ and Koropatnick J. IDO Downregulation Induces Sensitivity to Pemetrexed, Gemcitabine, FK866, and Methoxyamine in Human Cancer Cells. PloS one. 2015; 10:e0143435.

50. Zhai L, Spranger S, Binder DC, Gritsina G, Lauing KL, Giles FJ and Wainwright DA. Molecular Pathways: Targeting IDO1 and Other Tryptophan Dioxygenases for
Cancer Immunotherapy. Clinical cancer research. 2015; 21:5427-5433.

51. Izbicka E, Wheelhouse RT, Raymond E, Davidson KK, Lawrence RA, Sun D, Windle BE, Hurley LH and Von Hoff DD. Effects of cationic porphyrins as G-quadruplex interactive agents in human tumor cells. Cancer research. 1999; 59:639-644.

52. Wang Y, Jin TH, Farhana A, Freeman J, Estell K, Zmijewski JW, Gaggar A, Thannickal VJ, Schwiebert LM, Steyn AJ and Deshane JS. Exposure to cigarette smoke impacts myeloid-derived regulatory cell function and exacerbates airway hyper-responsiveness. Laboratory investigation. 2014; 94:1312-1325.

53. Takikawa O, Kuroiwa $\mathrm{T}$, Yamazaki $\mathrm{F}$ and Kido R. Mechanism of interferon-gamma action. Characterization of indoleamine 2,3-dioxygenase in cultured human cells induced by interferon-gamma and evaluation of the enzymemediated tryptophan degradation in its anticellular activity. The Journal of biological chemistry. 1988; 263:2041-2048.

54. Jeong YI, Kim SW, Jung ID, Lee JS, Chang JH, Lee CM, Chun SH, Yoon MS, Kim GT, Ryu SW, Kim JS, Shin YK, Lee WS, Shin HK, Lee JD and Park YM. Curcumin suppresses the induction of indoleamine 2,3-dioxygenase by blocking the Janus-activated kinase-protein kinase CdeltaSTAT1 signaling pathway in interferon-gamma-stimulated murine dendritic cells. The Journal of biological chemistry. 2009; 284:3700-3708. 